\section{Emergency ultrasonography of the gastrointestinal tract of children}

\author{
Jae-Yeon Hwang ${ }^{1,2}$ \\ ${ }^{1}$ Department of Radiology, ${ }^{2}$ Research Institute for Convergence of Biomedical Science and \\ Technology, Pusan National University Yangsan Hospital, Yangsan, Korea
}

Ultrasonography (US) is widely used to evaluate most body parts in pediatric patients because it is simple, noninvasive, easy to use, and applicable in a wide variety of clinical situations. US is the modality of choice for the initial evaluation of acute abdominal pain in pediatric patients because of their small body habitus and the presence of less fat tissue in the abdominal wall and peritoneal cavity. The most important factor in performing pediatric emergency US is the graded compression technique and selection of the proper transducer. The careful evaluation of bowel wall thickening combined with ancillary findings such as fluid collection, increased echogenicity of the mesenteric fat tissue, enlarged lymph nodes, hyperemic bowel changes, and abnormal bowel peristalsis can increase the diagnostic capability of US.

Keywords: Ultrasonography; Pediatrics; Emergencies; Gastrointestinal diseases; Radiology

\section{Introduction}

Ultrasonography (US) is widely used to evaluate most body parts in pediatric patients because it is simple, noninvasive, easy to use, and applicable in a wide variety of clinical situations. Moreover, in many clinical situations, it does not require any specific patient preparation or sedation. Using the Doppler technique, US offers high-resolution images and information about vascular flow that could be helpful for detailed evaluation of the gastrointestinal $(\mathrm{Gl})$ tract, even in patients with a small body habitus. An adequate sonic window provides superior image quality. With its ability to offer real-time imaging, US is useful for evaluating bowel peristalsis. This article presents the basic aspects of US for evaluating the pediatric GI tract, including techniques and the anatomy imaged. It then discusses the sonographic findings of frequently encountered in emergency settings.

\section{General Techniques}

Before starting a US examination, radiologists must be familiar with the clinical presentations of GI diseases that present as an emergency. The most common presentations are vomiting, pain, hematochezia, and diarrhea, with or without fever. Some diseases have typical clinical presentations, but many have overlapping symptoms and clinical appearances (Table 1). Therefore, understanding the clinical situation (e.g., the patient's age, history, and symptoms) and consultation with a pediatric emergency physician play important roles in arriving at an accurate diagnosis.

Choosing a proper transducer is an important factor in pediatric US. A high-frequency (7.5-12.0

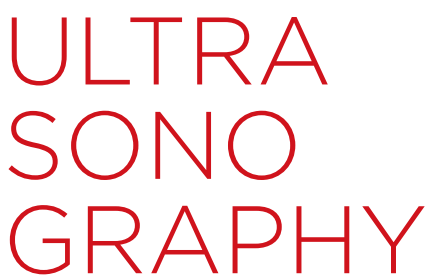

\section{REVIEW ARTICLE}

https://doi.org/10.14366/usg. 16052 pISSN: 2288-5919 • elSSN: 2288-5943 Ultrasonography 2017;36:204-221

Received: December 27, 2016

Revised: January 22, 2017

Accepted: January 25, 2017

Correspondence to: Jae-Yeon Hwang, MD, PhD, Department of Radiology, Pusan National University Yangsan Hospital, 20 Geumo-ro, Mulgeum-eup, Yangsan 50612 , Korea

Tel. $+82-55-360-1840$

Fax. +82-55-360-1848

E-mail: jyhwang79@gmail.com

This is an Open Access article distributed under the terms of the Creative Commons Attribution NonCommercial License (http://creativecommons.org/ licenses/by-nc/3.0/) which permits unrestricted noncommercial use, distribution, and reproduction in any medium, provided the original work is properly cited.

Copyright (C) 2017 Korean Society of Ultrasound in Medicine (KSUM)

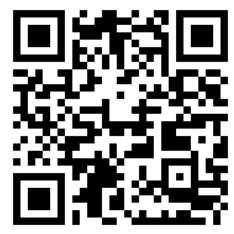

How to cite this article:

Hwang JY. Emergency ultrasonography of the gastrointestinal tract of children. Ultrasonography. 2017 Jul;36(3):204-221. 
Table 1. Approaches to pediatric emergency gastrointestinal disease according to symptoms

\begin{tabular}{ll}
\hline \multicolumn{1}{c}{ Symptom } & \multicolumn{1}{c}{ Differential diagnosis } \\
\hline Vomiting & $\begin{array}{l}\text { Midgut volvulus, hypertrophic pyloric stenosis, } \\
\text { intussusception, inflammation, Henoch-Schönlein } \\
\text { purpura } \\
\text { Pntussusception, appendicitis, mesenteric adenitis, } \\
\text { bowel obstruction, omental infarction }\end{array}$ \\
Hematochezia & $\begin{array}{l}\text { Intussusception, Meckel diverticulum, inflammation } \\
\text { Diarrhea }\end{array}$ \\
Fever & Infection, Crohn disease \\
\hline
\end{tabular}

$\mathrm{MHz}$ ) linear-array transducer is generally preferred for detecting GI problems within the scope of the penetration of the beam. It provides a sufficiently high to demonstrate bowel wall stratification and thickening. A smaller convex-array transducer $(5-8 \mathrm{MHz})$ is recommended for small children when the beam penetration of the high-frequency linear-array transducer is insufficient or exploration of the entire abdomen is required. Its smaller, rounder shape is also useful for compressing anatomical structures when necessary. A large convex-array transducer is used $(1-5 \mathrm{MHz})$ for general screening of the entire abdomen in large patients or those for whom the sonic window is poor because of obesity. However, it is not recommended for detailed evaluation of the $\mathrm{Gl}$ tract, because it would provide insufficient resolution.

Bowel gas can obscure the abdominal organs on US, especially in patients with abdominal distension and/or guarding. The graded compression technique is a simple, highly effective method for visualizing the bowel in such cases because it eliminates bowel gas, thereby decreasing the distance between the transducer and target organ. In addition, it can be used to isolate abnormal bowel segments by pushing aside adjacent normal bowel segments. Thus, graded compression has the additional value of differentiating abnormal bowel segments (e.g., in the presence of acute appendicitis or other bowel inflammation) from normal bowel segments [1-3]. Furthermore, when direct pressure is applied over abnormal bowel segments (e.g., in a patient with appendicitis or intussusception), a lack of compressibility and movability is found, whereas healthy bowel segments are compressed and shifted by the pressure exerted using the transducer. The graded compression technique should start with applying gentle pressure over the abdominal wall to avoid frightening a patient who is experiencing GI tenderness (Video clips 1, 2).

\section{Normal Anatomy}

Many GI diseases appear as bowel wall thickening, including inflammatory bowel disease, non-Hodgkin lymphoma, intussusception, and Henoch-Schönlein purpura (HSP). Normal bowel wall thickness is approximately 2-4 mm in adults [4], although it may vary depending on peristalsis and the degree of the distension. In addition, normal bowel wall thickness may change with age. In pediatric patients, the maximum thickness is $1.5 \mathrm{~mm}$ in the small bowel and $2.0 \mathrm{~mm}$ in the colon. A study showed that the normal neonatal bowel wall can be up to $2.6 \mathrm{~mm}$ thick [5]. Thus, a bowel wall thickness of $\geq 3 \mathrm{~mm}$ could be considered a hallmark of pathology in the small bowel. A wall thickness of $\geq 4 \mathrm{~mm}$ in the colon also indicates a pathological state [6]. On color Doppler, normal bowel walls rarely show vascularity, although flow may be increased after feeding.

The bowel wall has five layers: mucosa, muscularis mucosa, submucosa, muscularis propria, and an outer sheath known as the serosa. On US, the innermost, echogenic layer is regarded as the superficial mucosa or the mucosa-lumen interface. The next layer, which is hypoechoic, is the deep mucosa. The submucosa is seen as a hyperechoic layer and is most pronounced in the colon. The muscularis propria is a hypoechogenic ring that is prominent in the stomach wall. The outermost serosa is very thin and not easily seen on US (Fig. 1). Tissue harmonic imaging can offer better visualization of bowel wall stratification on US. The disadvantage of tissue harmonic imaging is that the beam penetration is limited (Fig. 2) [7].

The jejunum, particularly the proximal portion, is typically located in the left upper quadrant of the abdomen and is usually collapsed, with a prominent fold. The ileum has a less prominent fold than the jejunum, and internal fluid is frequently seen in normal patients. The terminal ileum has a thicker wall and a more prominent fold than other parts of the small bowel. In addition, the hypoechoic deep mucosa is accentuated on US. The terminal ileum and ileocecal valve are good landmarks for detecting the appendix (Fig. 3).

For differentiating the colon from the small bowel, it is necessary to note its location, lack of a fold, haustral marking, a thicker wall than that of the small bowel, and prominent submucosal and muscular layers. The ascending and descending colon are easily found in the vicinity of both paracolic gutters (Fig. 4), whereas the transverse colon is usually located at the inferior aspect of the lesser curvature of the stomach. The sigmoid colon is located in the left lower quadrant and traverses the left psoas muscle. This landmark may be useful for tracing the descending colon and rectosigmoid colon (Video clip 3).

\section{Intestinal Malrotation and Midgut Volvulus}

The normal fetal bowel rotates $270^{\circ}$ counterclockwise in utero. Any defect during this process results in abnormal positioning of the 


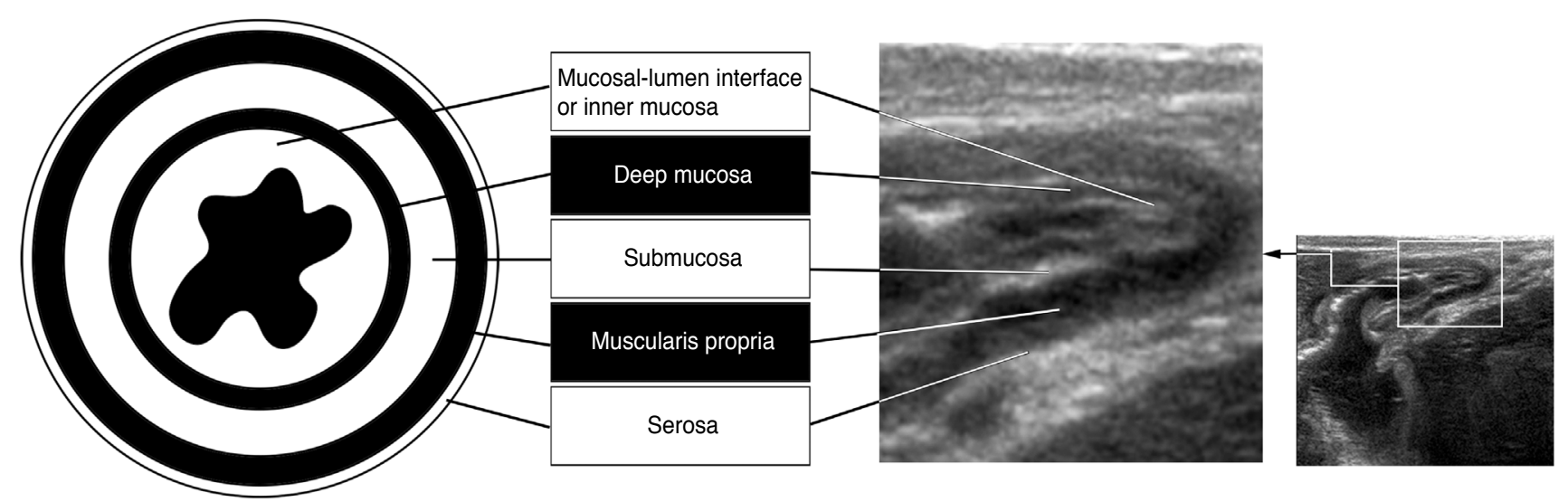

Fig. 1. Schema for normal bowel stratification using ultrasonography.

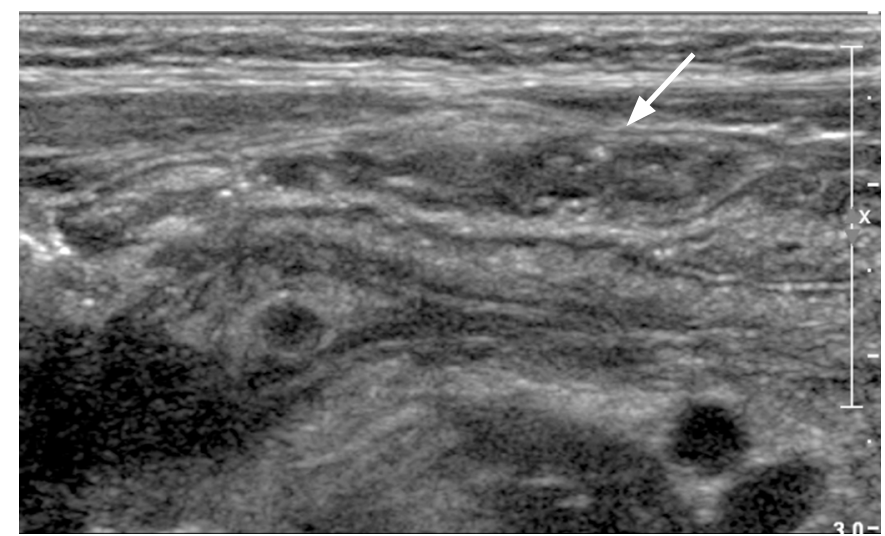

A

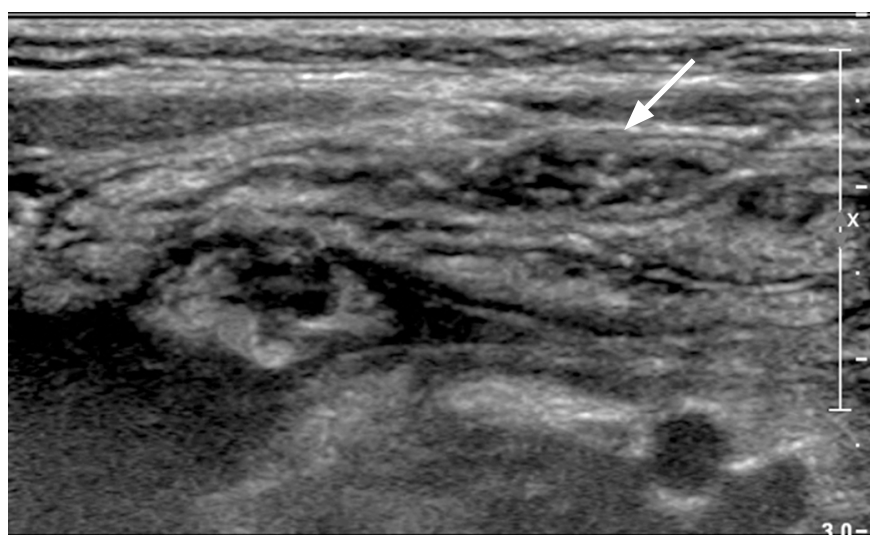

B

Fig. 2. Enhanced visualization of bowel stratification with tissue harmonic imaging.

A, B. A conventional grayscale image (A) and a tissue harmonic image (B) show terminal ileum (arrows).

duodenojejunal junction and ileocecal valve, short mesenteric root, and close location of the cecum and duodenum. If not diagnosed properly, it can lead to proximal bowel obstruction caused by either the Ladd band or midgut volvulus.

Although an upper Gl study remains the modality of a choice in such cases, US can be an alternative imaging modality $[8,9]$. An abnormal relation between the superior mesenteric artery (SMA) and superior mesenteric vein (SMV) is the sonographic hallmark for suspicion of intestinal malrotation.

For an US evaluation, the patient should be supine and the transducer applied at the upper midline of the abdomen using the graded compression technique. Normally, the SMV is located at the right anterior aspect of the SMA and is easily compressed by transducer pressure (Fig. 5). Color Doppler interrogation may help differentiate the two vessels. If the SMV is located ventrally or on the left side of the SMA, it is abnormally positioned (Fig. 6).
These abnormal locations, however, do not always imply intestinal malrotation.

Recently, it has been reported that the direct depiction of retroperitoneal positioning of the duodenal third portion or the duodenojejunal junction in the left upper quadrant of the abdomen is an alternative diagnostic indication of intestinal malrotation (Fig. 7) [8]. Demonstrating this abnormality is usually feasible in pediatric patients using the graded compression technique. Drinking some water may facilitate the visualization of the normal course of the third portion of the duodenum. This technique of visualizing the duodenal third portion on US, however, is highly operator-dependent (Video clip 4). When the US result is inconclusive or abnormal, an upper Gl study should be performed to confirm the diagnosis because a sonographic diagnosis cannot completely exclude intestinal malrotation $[8,10]$.

Midgut volvulus is a lethal complication of intestinal malrotation, 


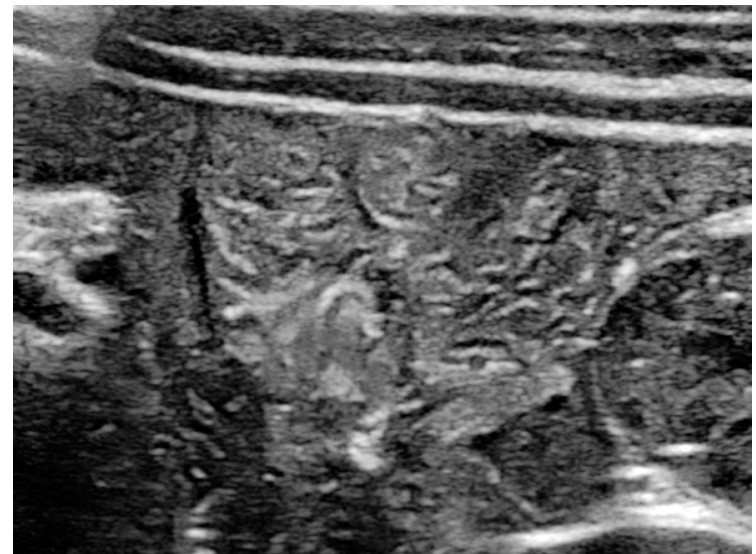

A

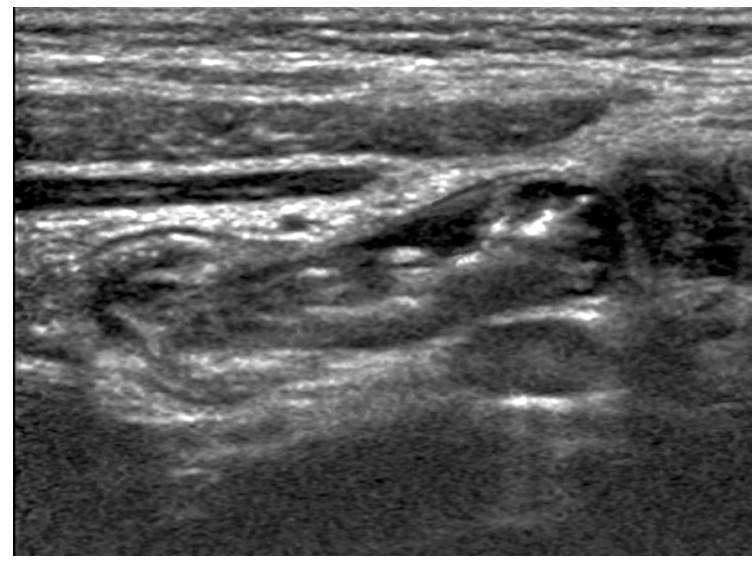

C

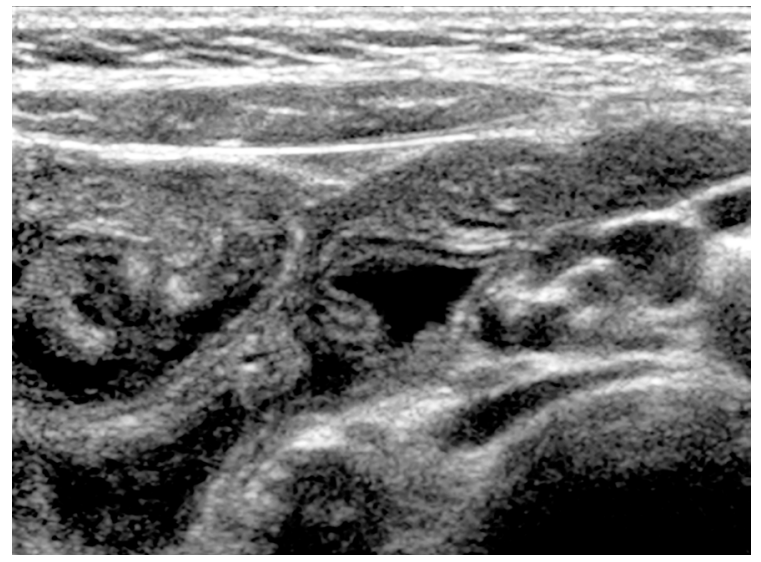

B

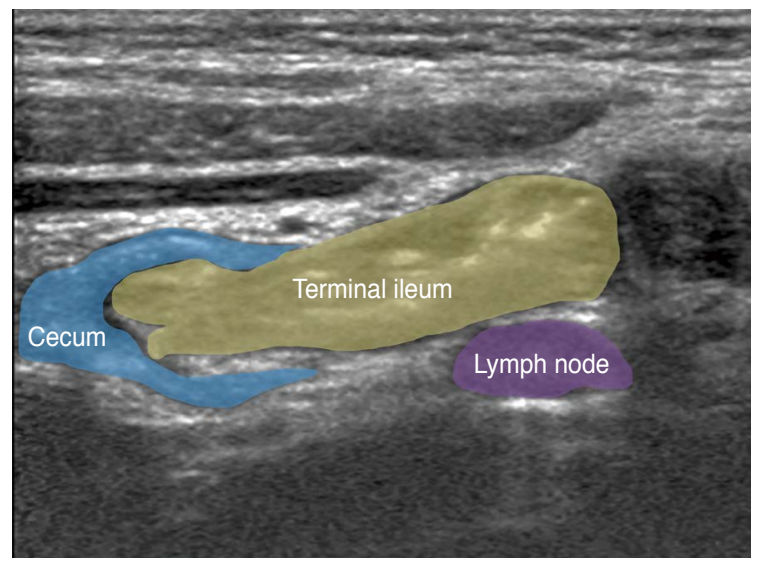

D

Fig. 3. Sonogram of the small bowel.

$A-D$. Sonograms show the jejunum (A), ileum (B), terminal ileum and ileocecal valve $(C, D)$.

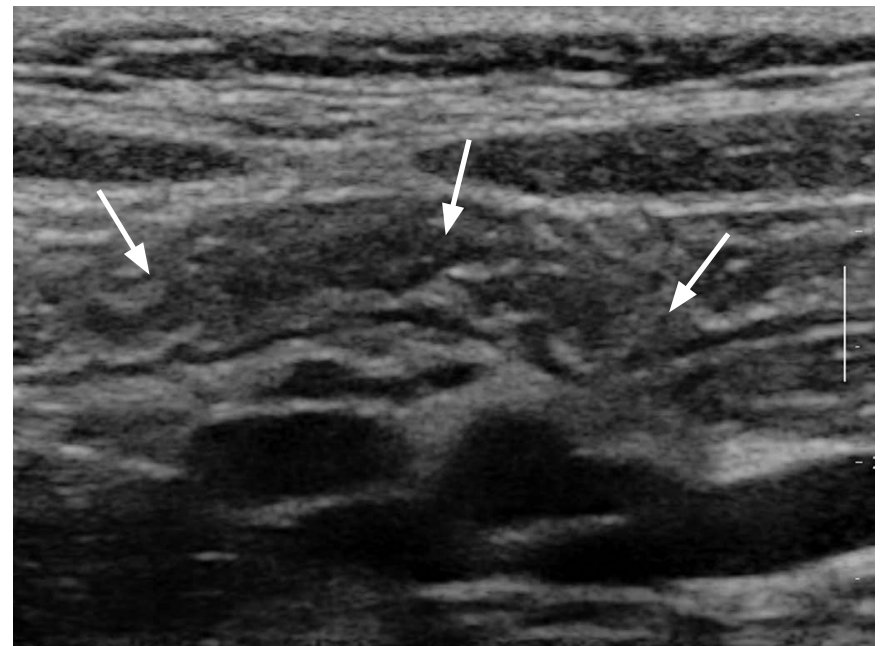

A

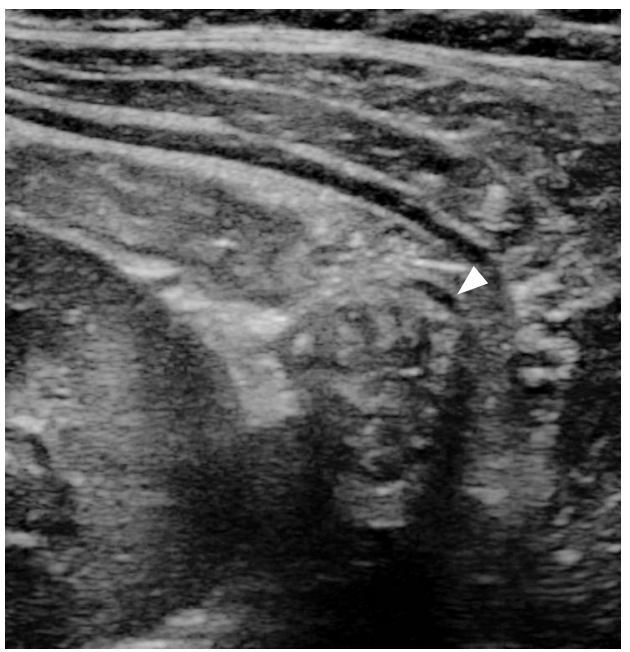

B

Fig. 4. Sonogram of the colon.

A, B. Sonograms show the transverse colon (arrows) (A) and the descending colon (arrowhead) (B). Note the haustral markings, prominent echogenic submucosa, and peripheral location of the colon. 


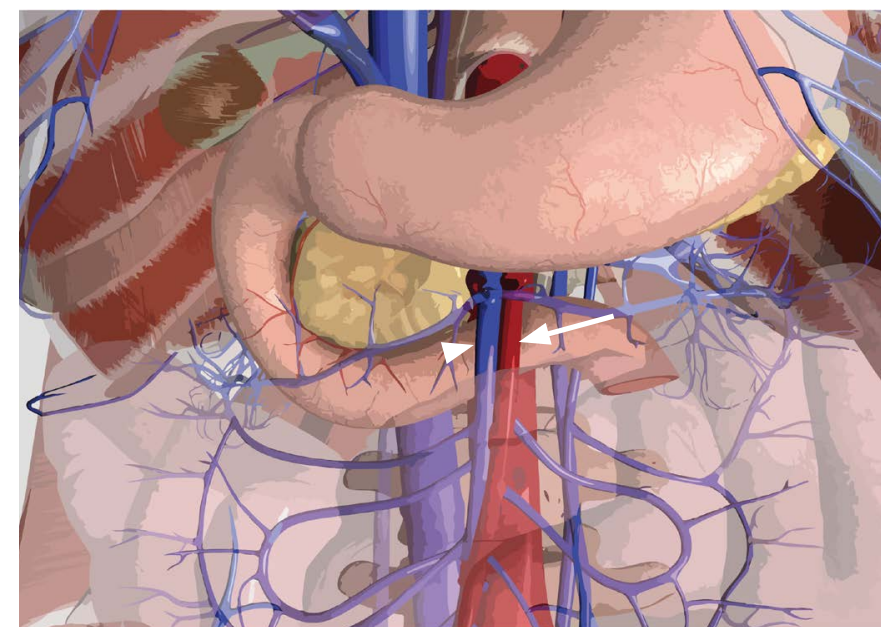

A

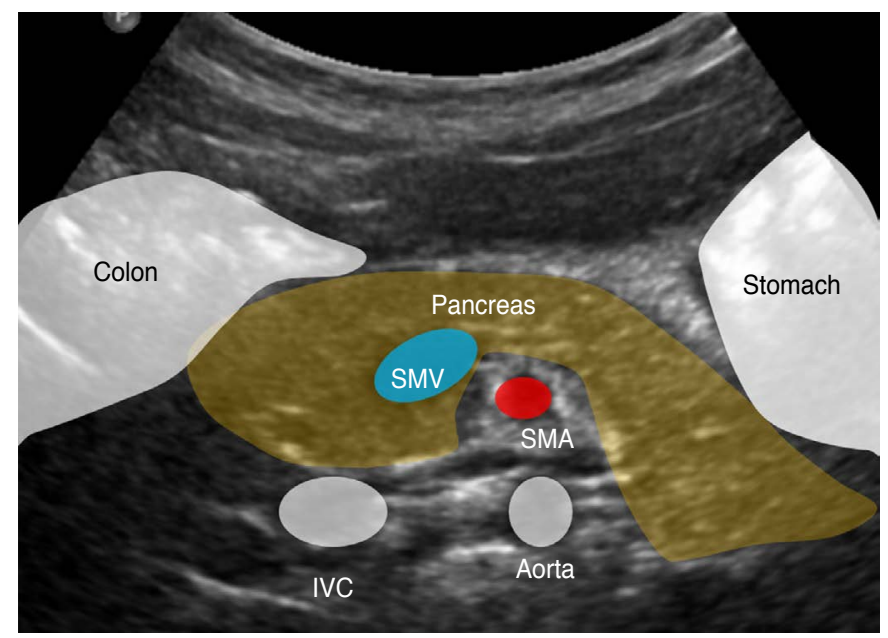

C

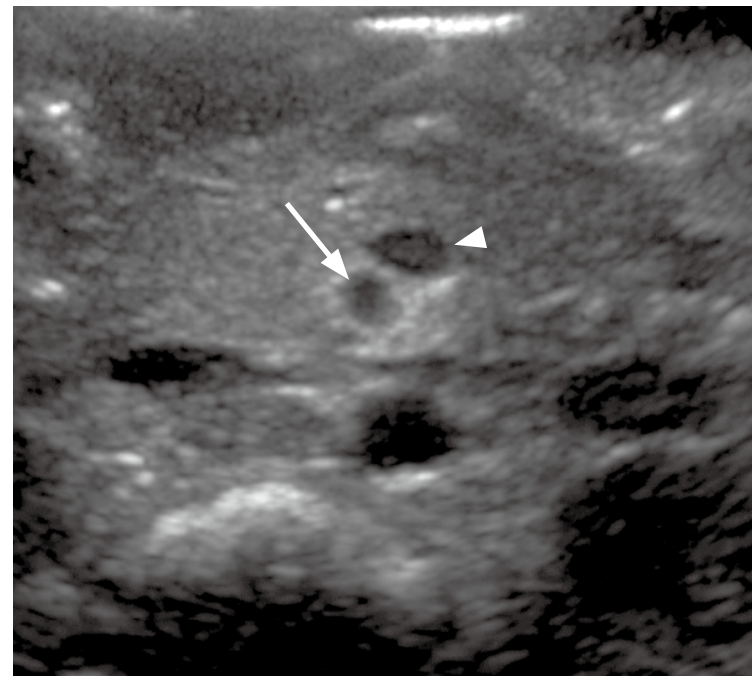

A

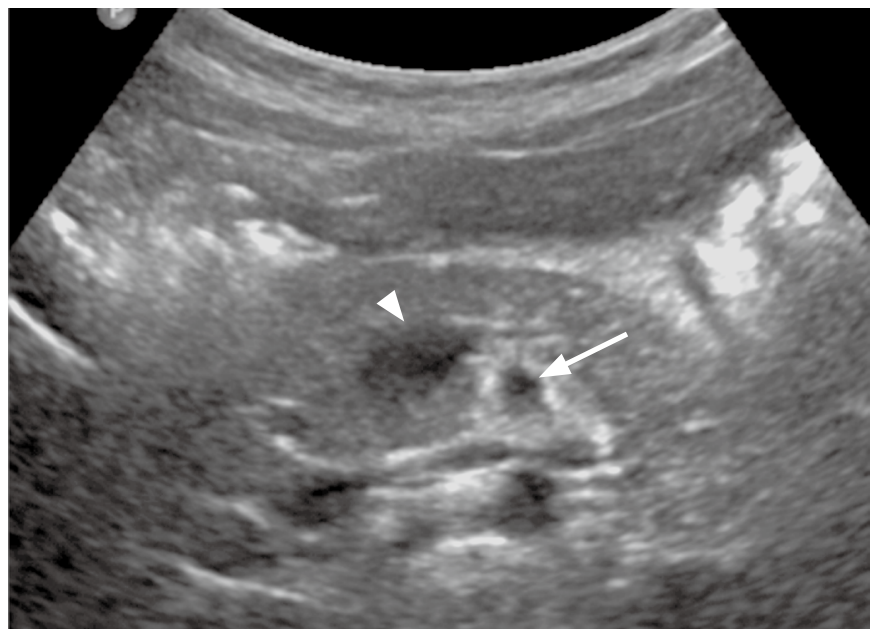

B

Fig. 5. Normal position of the superior mesenteric artery (SMA), superior mesenteric vein (SMV), and duodenal third portion. A. An illustration shows normal relationship of the SMA (arrow), SMV (arrowhead), and duodenal third portion. B, C. On a grayscale image, the SMV (arrowhead) is larger than the SMA (arrow) and is more compressible by pressure from the transducer. IVC, inferior vena cava.

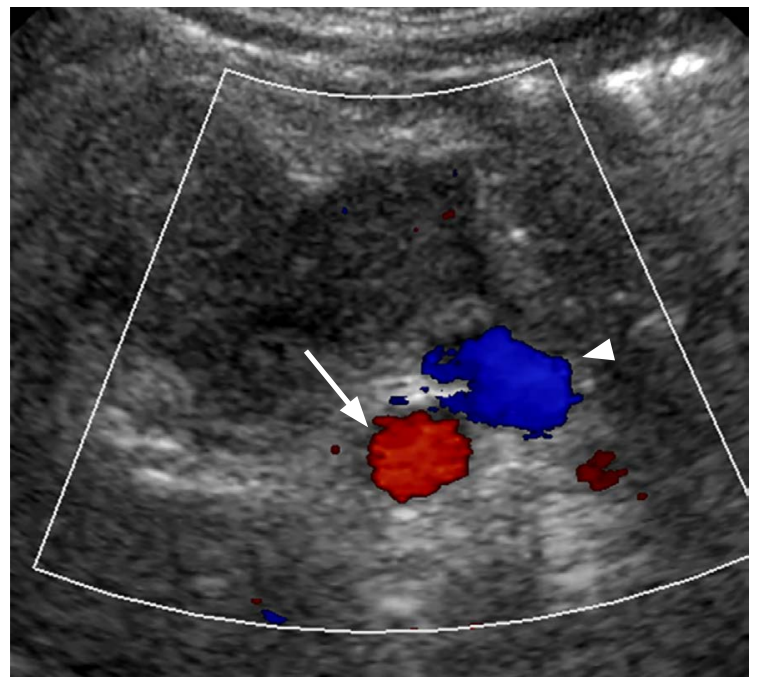

B

Fig. 6. Abnormal position of the superior mesenteric artery (SMA) and superior mesenteric vein (SMV).

A, B. A grayscale image (A) and color Doppler image (B) show the SMV (arrowheads) located at the left side of the SMA (arrows). 
resulting in proximal bowel obstruction and ischemia. Approximately $75 \%$ of cases occur within a month after birth (mostly within the first week) and $90 \%$ within 1 year. The sonographic hallmark of midgut volvulus is the "whirlpool" sign, which refers to the clockwise twisting of the SMV, mesentery, and duodenum around the SMA. A color Doppler study may help identify the relation between the SMV and SMA (Video clip 5). The ancillary findings of midgut volvulus are a thickened echogenic bowel wall due to edema or hemorrhage, a fluid-filled duodenum with varying degrees of distension, and hyperpulsatile SMA shown on a Doppler study. If this sign is positive, an upper GI study should be performed promptly, followed by surgery (Fig. 8).

A common cause of false-positive results when diagnosing intestinal malrotation is off-center scanning. If the transducer is not properly applied in the midline of the abdomen, the relation of the SMV and SMA may seem to be abnormal (Video clip 6). Another false-positive diagnosis is when the "whirlpool" sign corresponds to the normal counterclockwise rotation of the SMV around the SMA. This counterclockwise rotation of the jejunal branch of the SMV is frequently encountered in normal patients and does not always accompany rotation of the duodenum or small bowel (Video clip 7).

Severe abdominal distension, abdominal guarding, abundant bowel gas, and/or an inexperienced operator can lead to falsenegative diagnoses. In these situations, using a more gentle, graded compression technique, a convex transducer, limited sedation, and an emergency upper GI study could be helpful for clarifying the diagnosis.

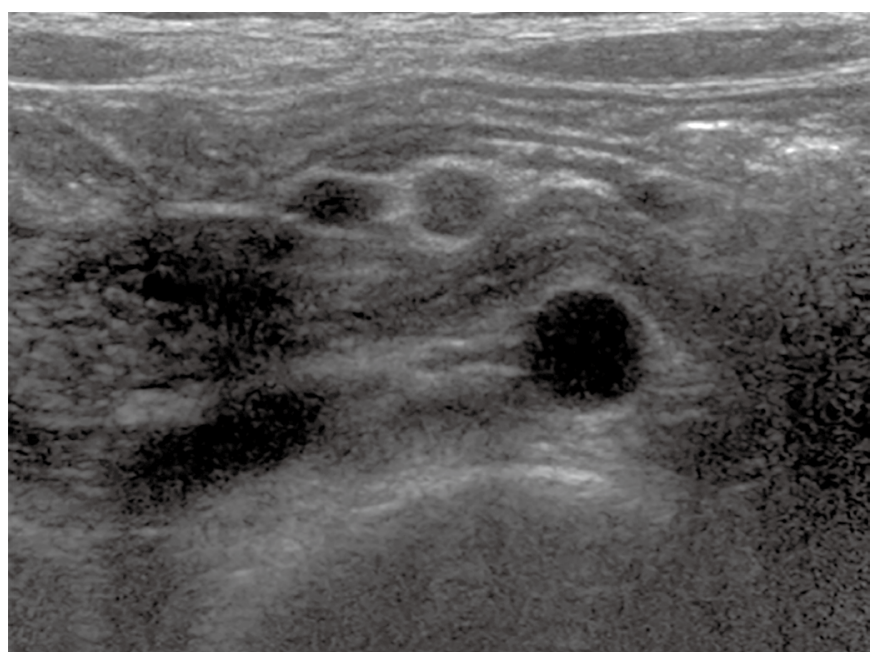

A

\section{Hypertrophic Pyloric Stenosis}

Hypertrophic pyloric stenosis (HPS) is the most common reason for conducting surgery in infants [11]. The typical symptom of HPS is non-bilious, intermittent, projectile vomiting by a previously healthy infant. HPS is not a frank emergency disease unless complications such as severe dehydration and electrolyte imbalance occur. Symptoms usually appear during the fourth week after birth, but the timing may range from the third to the twelfth week. US is the imaging modality of choice for diagnosing HPS, with sensitivity and specificity of approximately 100\% [12-15].

The US examination starts with placing the patient in a supine position. A high-frequency linear-array transducer is applied to the epigastric area. Scanning downward, the operator should start at the liver and gastroesophageal junction and continue to the falciform ligament of the liver and fissure for the ligamentum venosum. With careful scanning, the normal pylorus is seen between the liver and head of the pancreas (Video clip 8). When the sonic window is poor because of abundant gas in the gastric antrum, duodenal bulb, or transverse colon, the patient should be moved into the right lateral decubitus position, which allows visualization of the pylorus with shifting of the fluid into the antropyloric canal and displacement of the pylorus anteriorly while the gas moves into the gastric fundus. In addition, after filling of the stomach with a glucose solution or water, it is possible to evaluate passage of the fluid through the pylorus (Video clip 9).

A pyloric muscle thickness of $>3 \mathrm{~mm}$ and a channel length of $>17 \mathrm{~mm}$ offer high diagnostic accuracy $[16,17]$. The pylorus is

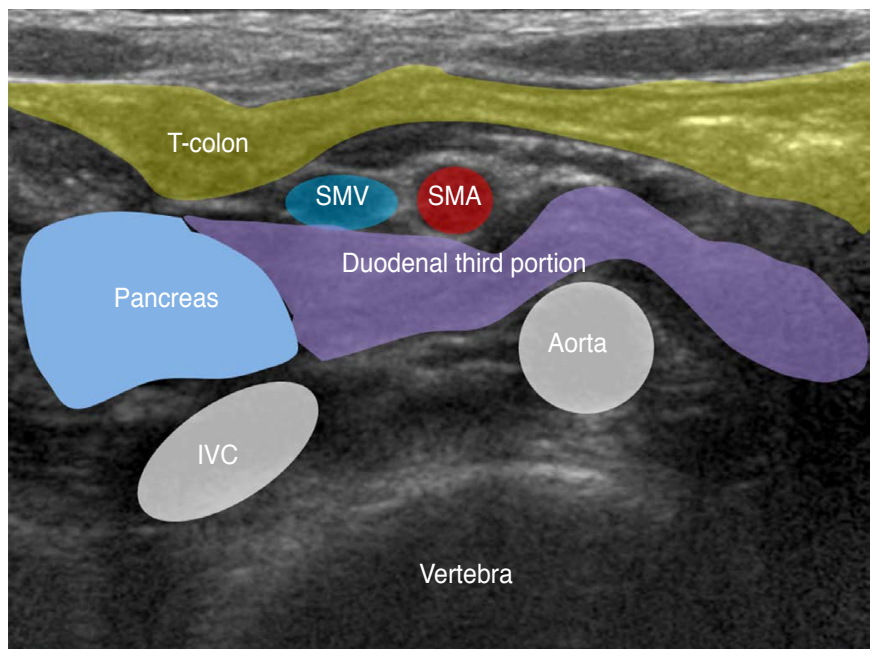

B

Fig. 7. Normal retroperitoneal course of the duodenal third portion.

A, B. A sonogram (A) and an illustration (B) shows normal retroperitoneal course of the duodenal third portion. T-colon, transverse colon; SMV, superior mesenteric vein; SMA, superior mesenteric artery; IVC, inferior vena cava. 
a dynamic structure, and the thickness and length of the pyloric muscle can change during a real-time US examination. Hence, a muscle thickness $>3 \mathrm{~mm}$ throughout the examination and failure to distend the pyloric channel with peristaltic gastric movement and minimal gastric emptying, prolapsed mucosa into the gastric antrum (the antral nipple sign), and trapped fluid within the crevices of the mucosa (the double track sign) are unequivocal findings associated with HPS (Fig. 9). Sonographic measurement is most accurate at the center of the short-axis view. Measurement of the longitudinal view may result in a false-positive result due to an off-center measurement. The measurement should include only the hypoechoic muscular layer.

When the muscle thickness is between $2 \mathrm{~mm}$ and $3 \mathrm{~mm}$, it is deemed an equivocal finding. In such a case, a diagnosis of pylorospasm or evolving HPS is considered. If the pyloric muscle thickness is normalized and a pyloric channel opening is observed

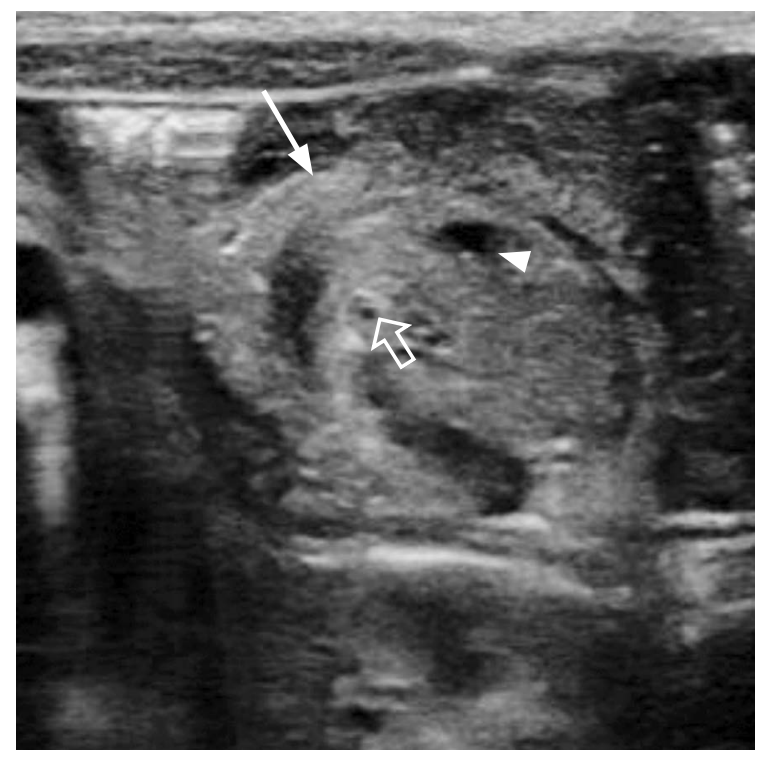

A

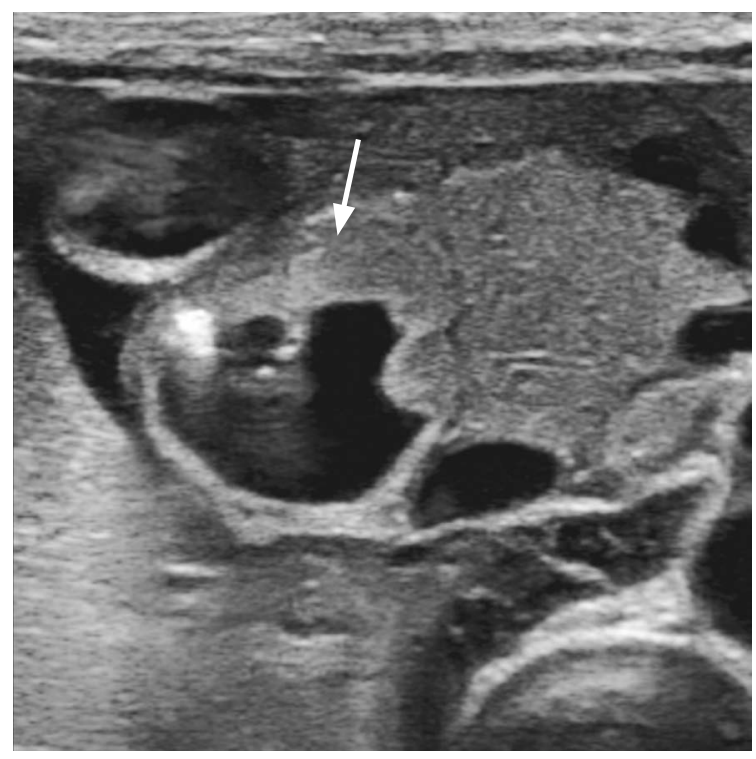

C

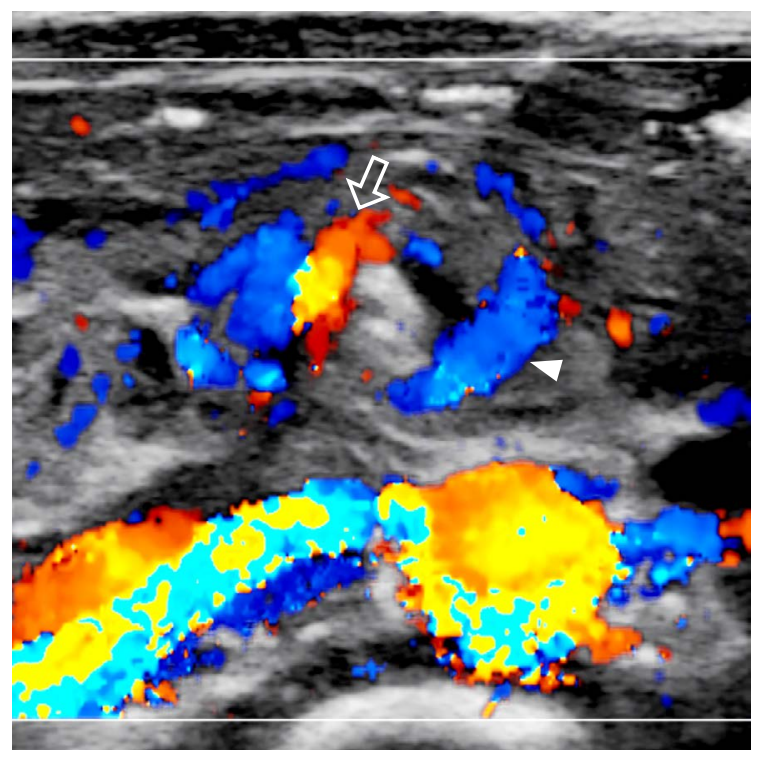

B

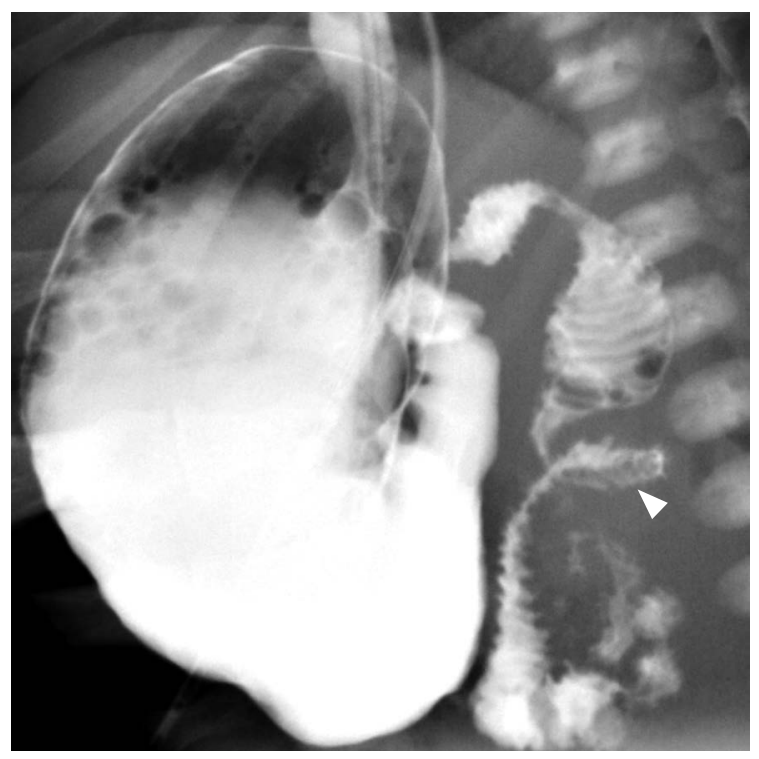

D

Fig. 8. Sonogram of the whirlpool sign.

A, B. A grayscale image (A) and color Doppler image (B) show the clockwise rotation of the duodenum (arrow) and superior mesenteric vein (arrowheads) around the superior mesenteric artery (open arrows). C. A sonogram shows duodenum which was dilated by filling it with fluid (arrow). D. A barium study shows corkscrew appearance (arrowhead) of the duodenum and proximal dilatation. 
during a prolonged examination, pylorospasm may be considered. If the muscle thickness is consistently borderline during a prolonged examination; however, delayed US (2-4 weeks later) should be undertaken in order to avoid missing frank HPS $[15,16]$.

The major cause of a false-negative result is an overly distended stomach because the antropyloric canal is posteriorly directed in the deep location of the abdomen (Fig. 10). Moving the patient into the left lateral decubitus position may allow the fluid to shift into the stomach fundus with anterior displacement of the pyloric channel. In addition, aspiration of the gastric content if the patient has a nasogastric or orogastric tube or the use of a convex transducer could be helpful for visualizing the pylorus.

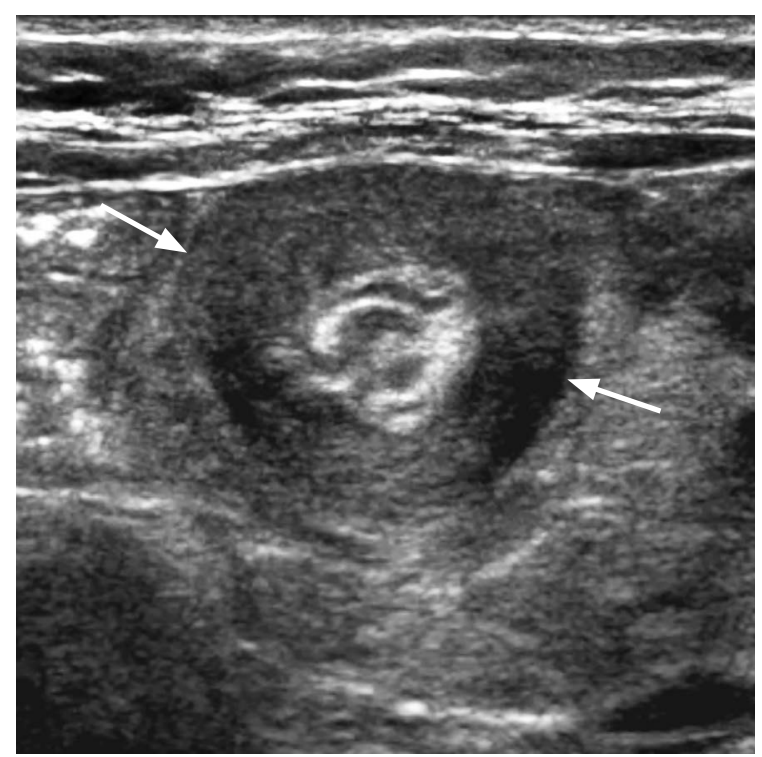

A

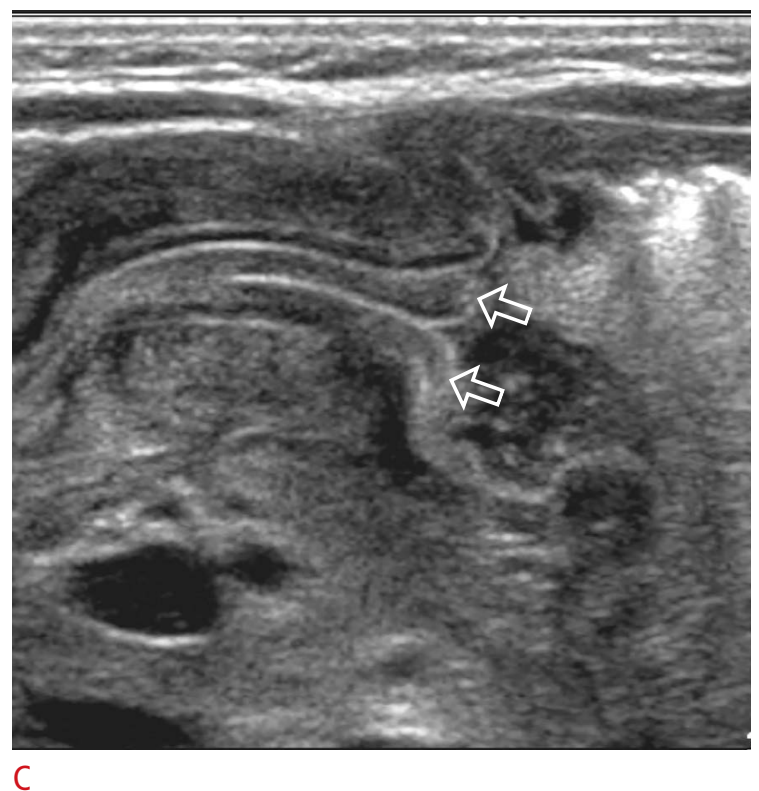

\section{Intussusception}

Intussusception is the most common cause of small bowel obstruction in infants, with $60 \%$ of cases occurring during the first year of life and $90 \%$ in those $<2$ years of age [18]. Both the sensitivity and specificity of US reach up to $100 \%$ [19]. Although most intussusceptions in infants are idiopathic, they may also be due to hypertrophied lymphoid tissue in the terminal ileum. Approximately $25 \%$ of these pediatric patients have a focal mass or diffuse bowel wall abnormality, such as pathological lead points.

lleocecal intussusception usually occurs in the subhepatic region in the right upper quadrant of the abdomen, although it has also

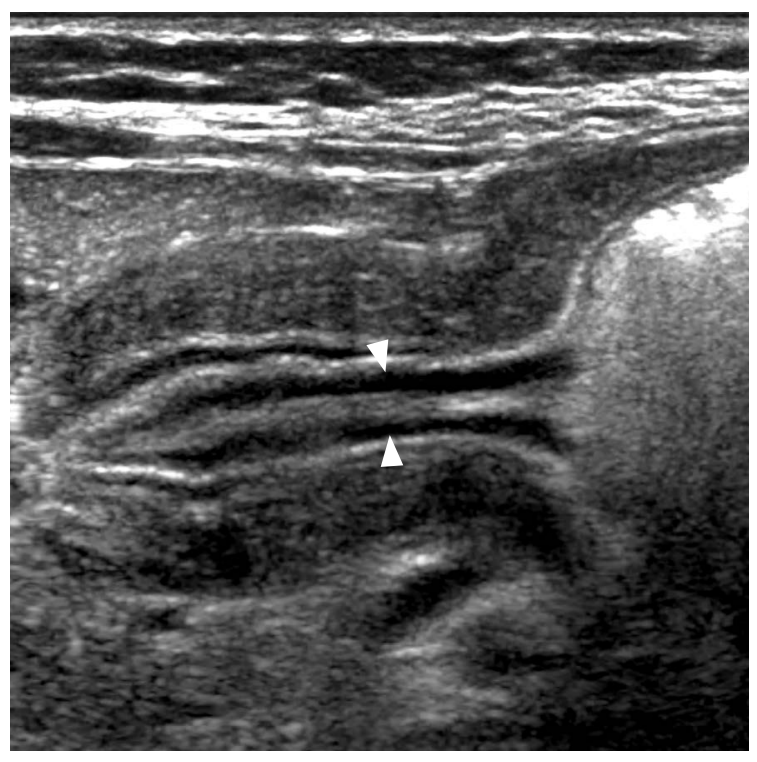

B

Fig. 9. Hypertrophic pyloric stenosis in a 2-week-old patient.

A, B. Transverse (A) and longitudinal (B) views show concentric hypertrophy of the muscular layer of the pyloric canal (arrows). Note the double track sign (arrowheads) and distended stomach despite fasting for 2 hours. C. A longitudinal image shows the antral nipple sign, which refers to prolapse of the echogenic mucosa into the antral space (open arrows). 


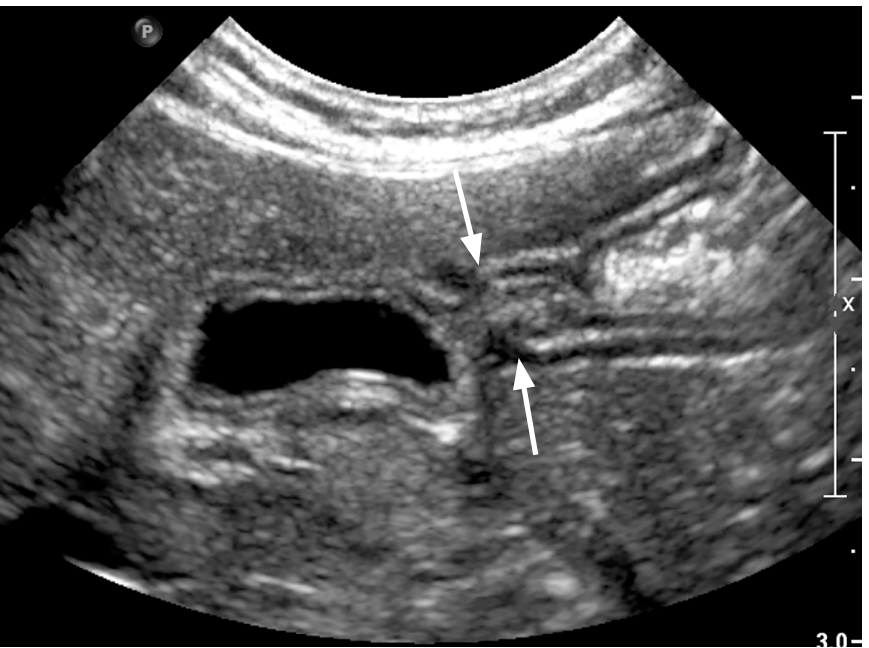

A

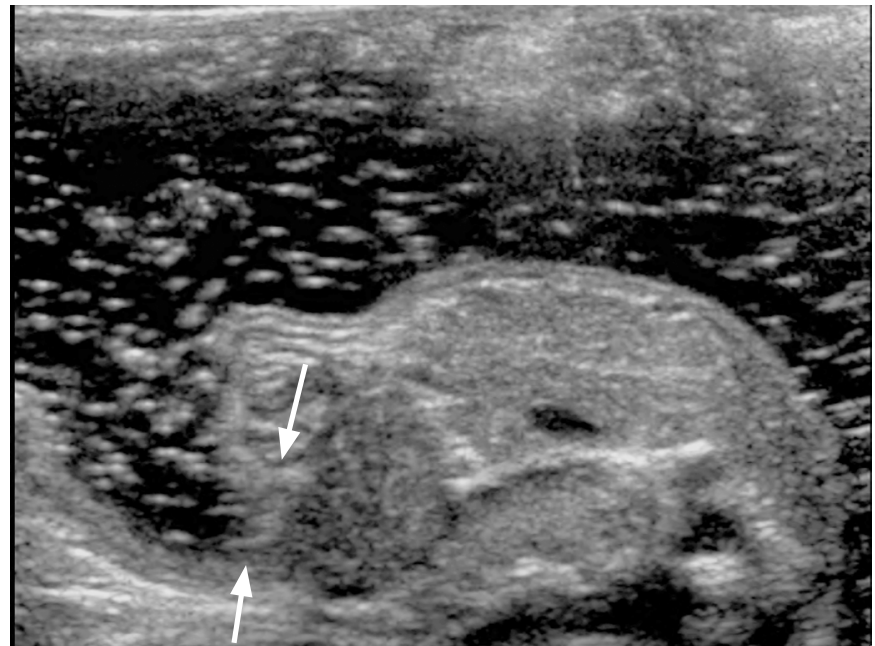

B

Fig. 10. Changing direction of the pyloric canal after feeding.

A. Before milk feeding, the pylorus (arrows) is directed to the right side and anteriorly. B. After feeding, the axis of the pyloric canal (arrows) is directed left and posteriorly.

been detected at the upper abdominal midline and the left upper quadrant. If US does not detect intussusception, the entire abdomen should be explored by US to find other causes of the abdominal pain. Again, the graded compression technique is essential to detect intussusception by pushing healthy bowel segments out of the way and removing bowel gas from the adjacent $\mathrm{Gl}$ tract.

Simple ileocolic intussusception consists of three bowel segments. The entering and returning limbs of the intussusceptum are the terminal ileum, and the outermost intussuscipiens is the colon. US has revealed that the most thickened segment is the returning limb of the intussusceptum (owing to a compromised vascular supply). The mesentery and lymph nodes (LNs) are frequently seen between two segments of the intussusceptum (Fig. 11).

On axial scanning of the leading edge of the intussusceptum, a doughnut sign may be present due to the peripheral hypoechoic rim being separated from the central limb of the intussusceptum by the serosa and mesentery. More proximally, various echoic bowel layers may be seen, and there are variable amounts of echogenic mesentery containing mesenteric LNs that are pulled along with the entering limb of the intussusceptum (Fig. 11).

In addition to detecting intussusception, US can predict its reducibility by enema reduction. The likely causes of poor reducibility are reduced vascular flow (seen during a color Doppler study), trapped peritoneal fluid within the intussusceptum, thickened outer wall (>10 mm), at least two LNs trapped in the intussusceptum with any LN size $>11 \mathrm{~mm}$, and the presence of a pathological lead point $[6,19,20]$. In addition, the presence of intramural or subserosal gas indicates a risk of bowel necrosis and perforation. The only contraindications for enema reduction are the presence of peritonitis and free air in the abdomen.

It has been reported that US could identify approximately twothirds of pathological lead points [21]. Meckel diverticulum, duplication cyst, polyp, lymphoma, and intramural hematoma of HSP are common pathologic lead points (Fig. 12). Care should be taken not to miss a pathological lead point in unusual clinical settings, such as in a patient who does not fall into the usual age group (e.g., $<1$ month old or $>5$ years old), has an abnormal type of intussusception (colocolic, small bowel intussusception), has a long duration of symptoms, or is experiencing recurrence.

Transient small bowel intussusception is sometimes detected incidentally. Most cases of transient intussusception are due to small bowel hyperperistalsis. They are usually smaller than ileocecal intussusception $(<1 \mathrm{~cm}$ in diameter) and are located in the periumbilical, left upper quadrant, or left lower quadrant of the abdomen. Repeated or prolonged examination is recommended for determining if the lesion has resolved. If the lesion is persistent and symptomatic, with long segmental involvement of $>3.5 \mathrm{~cm}$, the patient should be carefully evaluated to identify the pathological lead point [22].

\section{Acute Appendicitis}

Acute appendicitis is the most common condition that requires abdominal surgery in children. Unlike adults, approximately onethird of patients present with nonspecific symptoms, such as fever, diarrhea, and vague abdominal pain, which may lead to 
misdiagnosis. Advanced disease is frequent in younger children ( $<6$ years) because of their inability to communicate about their symptoms. Therefore, perforation rates are higher in these younger patients: $83 \%$ among neonates and $51 \%-100 \%$ among children $<5$ years of age [23-26]. The sensitivity and specificity of US for diagnosing appendicitis are $80 \%-95 \%$ and $90 \%-100 \%$, respectively [6].

A high-frequency linear-array transducer is necessary when using the graded compression technique. Slow compression at the site of maximum tenderness to optimize patient tolerance is important. In addition, sudden release of the transducer should be avoided to prevent rebound tenderness. A convex-array transducer (1-5 $\mathrm{MHz}$ ) could be an alternative when the sonic window is poor or the appendix is suspected to be located in the retrocecal area.

The ileocecal valve is a good landmark for identifying the appendix. The base of the appendix is almost always located at the

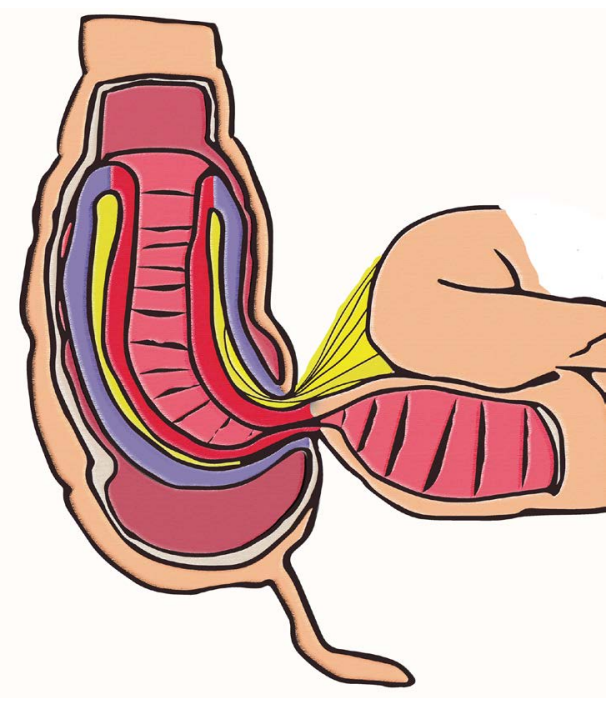

A

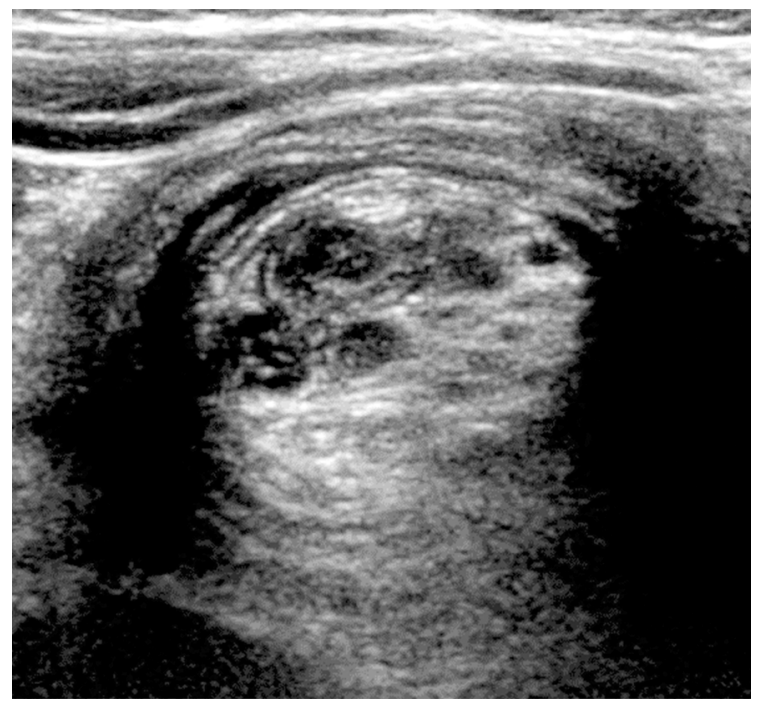

C

B
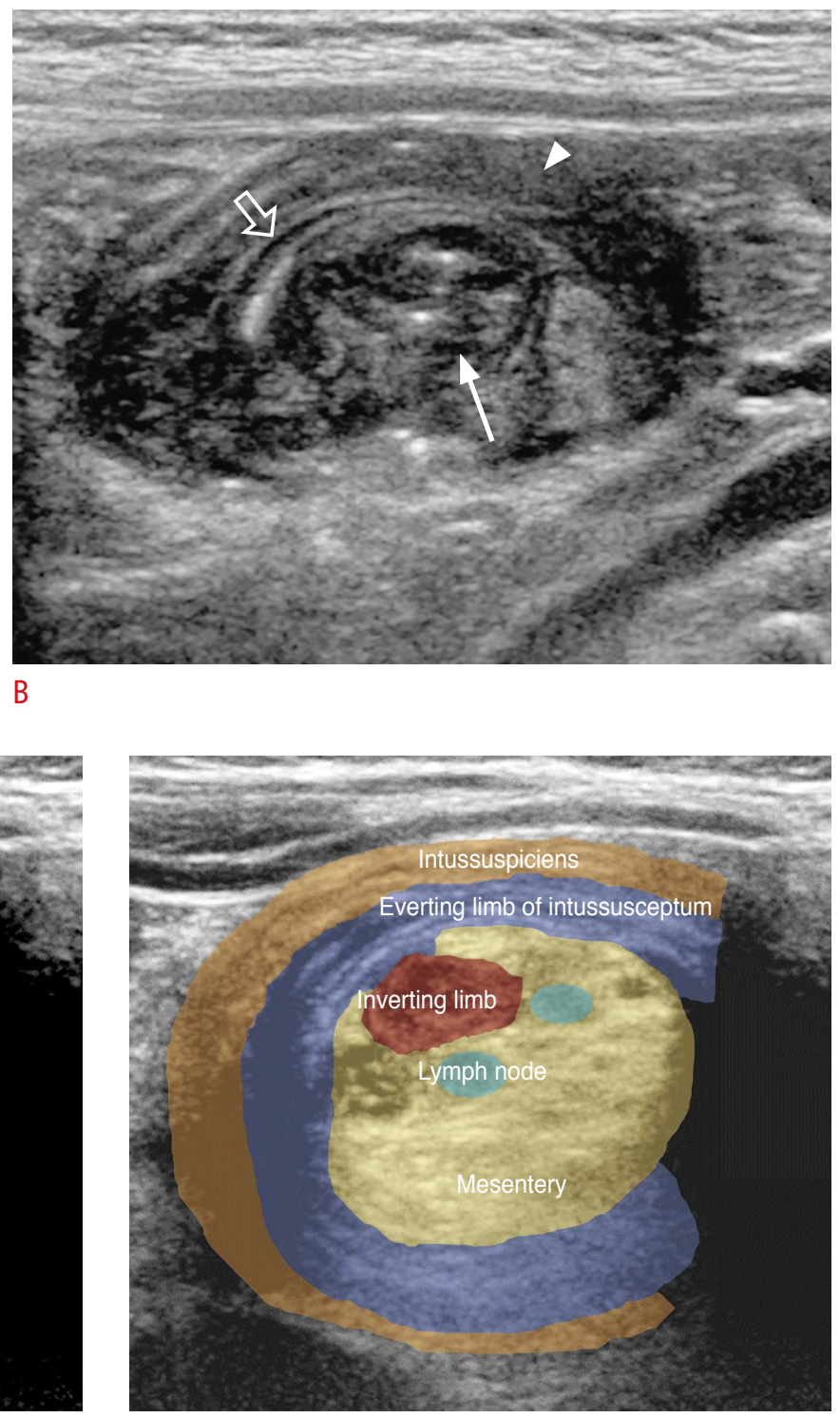

D

Fig. 11. Ileocolic intussusception.

A. Three layers of intussusception are as follows: inverting limb (red) and everting limb (violet) of the intussusceptum and intussuscipiens (consistent with the colon). Note the mesentery (yellow) incorporated between the two limbs of the intussusceptum. B. At the leading edge of the intussusception, the central intussusceptum (arrow) and peripheral intussuscipiens (arrowhead) make a doughnut sign. The central intussusceptum is separated with echogenic lines by the serosa and mesentery (open arrow). C, D. More proximally, various layers of the intussusceptum and intussuscipiens are seen with mesenteric fat. 


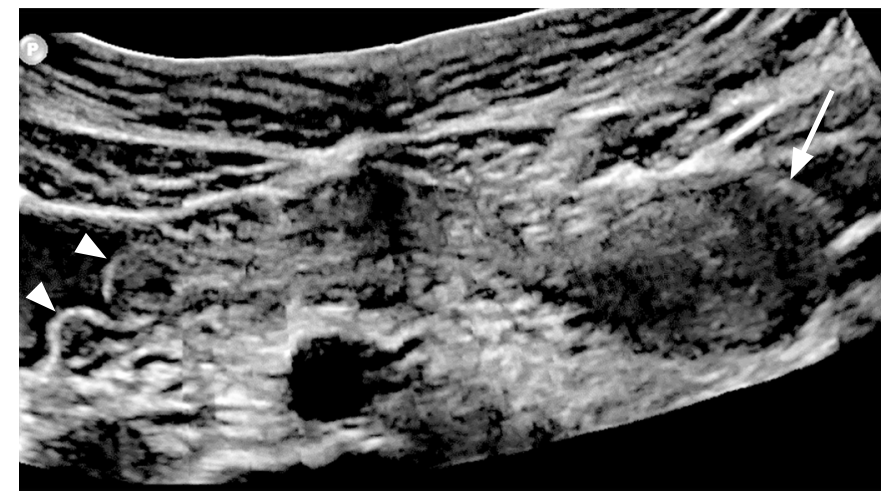

A

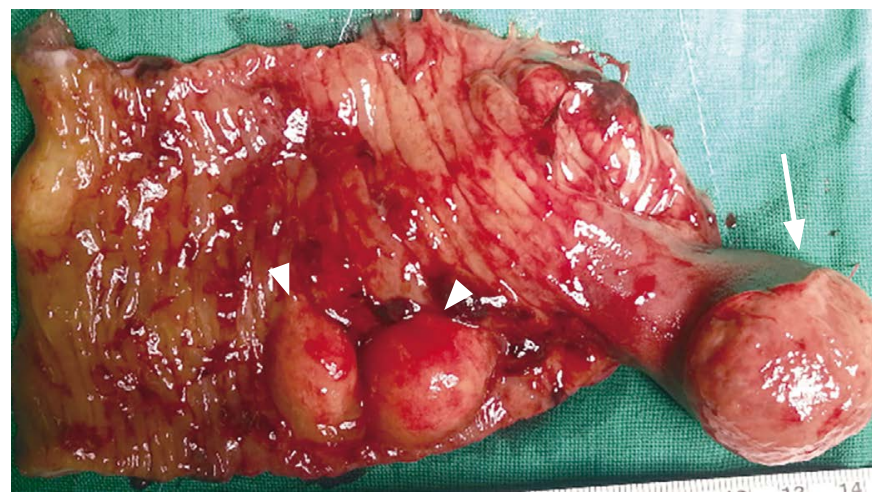

B

Fig. 12. A 7-year-old boy with small bowel intussusception.

A. A sonogram shows a small bowel intussusception with one pedunculated polyp (arrow) and two sessile polyps (arrowheads) as pathological leading points. B. Surgical specimen reveals the same findings that are seen on the sonogram. Note the pedunculated (arrow) and sessile polyps (arrowheads).

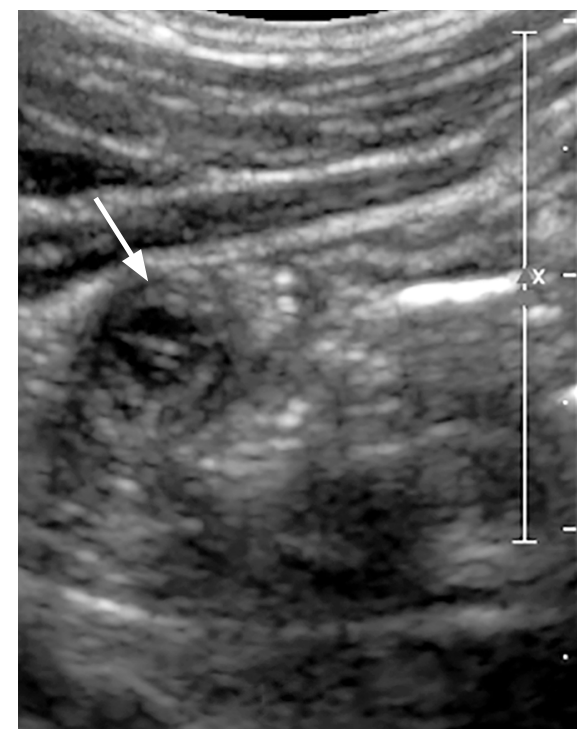

A

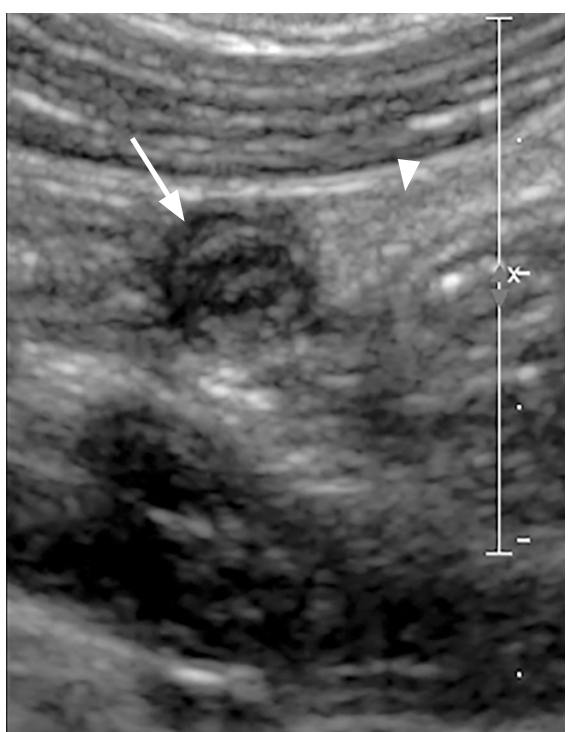

B
Fig. 13. Acute appendicitis.

A, B. A sonogram with no compression (A) and compression (B) show a noncompressible dilated appendix $>6 \mathrm{~mm}$ in diameter (arrows). Note the thickening of the echogenic submucosa of the appendix and increased echogenicity of the periappendiceal fat (arrowhead). medial portion of the cecum, just caudal to the ileocecal valve. The location of the appendix tip, however, varies. After localizing the ileocecal valve, the appendix base can be found by scanning down 1-2 cm from the ileocecal valve or terminal ileum (Video clip 10). If the appendix is a pelvic brim type, it lays over the right psoas muscle (Video clip 11). Thickened, deep mucosa, a prominent fold, and the presence of peristaltic movements of the terminal ileum are clues for differentiating the appendix.

The posterior compression technique is helpful because it displaces the appendix and psoas muscle anteriorly [1,27] (Video clip 12). If the cecum is located in the lower pelvic cavity, changing the amount of fluid in the bladder or the transducer may be effective. For example, changing the patient's position to a left or right lateral decubitus posture may displace the tip of the appendix and cecum.

The normal appendix has a diameter of $\leq 6 \mathrm{~mm}$ and is compressible using the graded compression technique. An echogenic line that represents the luminal interface is located at the central portion of the appendix. The normal appendix wall thickness is $<3$ $\mathrm{mm}$. A varying amount of luminal air or fluid can be seen $[6,19,28]$.

The most reliable sonographic findings associated with appendicitis are loss of compressibility and a maximum outer diameter $>6$ mm (Fig. 13, Video clip 13). Ancillary findings are a target-like appearance in the short axis view, thickening of the echogenic submucosa, a fluid-filled lumen, the presence of appendicoliths, increased periappendiceal echogenicity, enlarged 
mesenteric LNs, and a small amount of pericecal or periappendiceal fluid. Hyperemia may be seen on a color Doppler study (Fig. 14) $[19,29,30]$.

If inflammation is advanced and suppurative appendicitis has evolved, heterogeneous echogenicity and hyperemic changes in the periappendiceal tissue may be present. Gangrenous changes are suggested by the presence of increasing appendiceal dilatation and loss of the echogenic submucosal layer with a lack of vascularity on a Doppler study (Fig. 15). In addition, perforation is suggested in the presence of inflammatory phlegmon seen as a mass with mixed echogenicity, poorly defined bowel loops in the right lower quadrant, focal bowel wall thickening, intraperitoneal fluid, loculated fluid collection, or abscess formation. It may be difficult to visualize an inflamed appendix when perforation has occurred (Fig. 16).

Tracing the entire appendix is important to prevent false-negative diagnoses. Inflammatory changes may be limited to the tip of the appendix, which is seen as a tubular structure ending in a blind pouch (Video clip 14). A retrocecal perforated appendix also can cause false-negative results. Secondary inflammation of the appendix due to Crohn disease or enterocolitis can produce false-

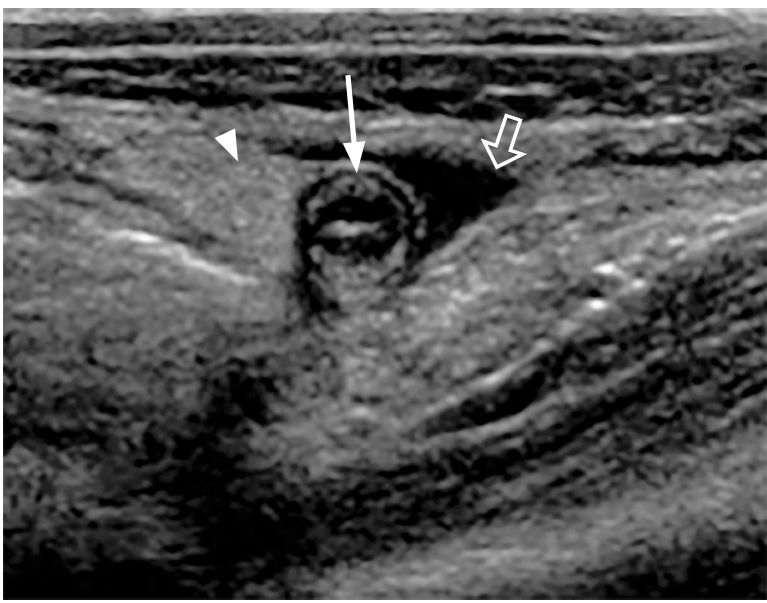

A

Fig. 14. Ancillary findings of acute appendicitis.

A. A short-axis view shows a target-like appearance of the appendix (arrow) with prominent periappendiceal fat (arrowhead) and a small amount of periappendiceal fluid (open arrow). B. A long-axis view with color Doppler shows thickening of the echogenic submucosa and mural hyperemia of the appendix.

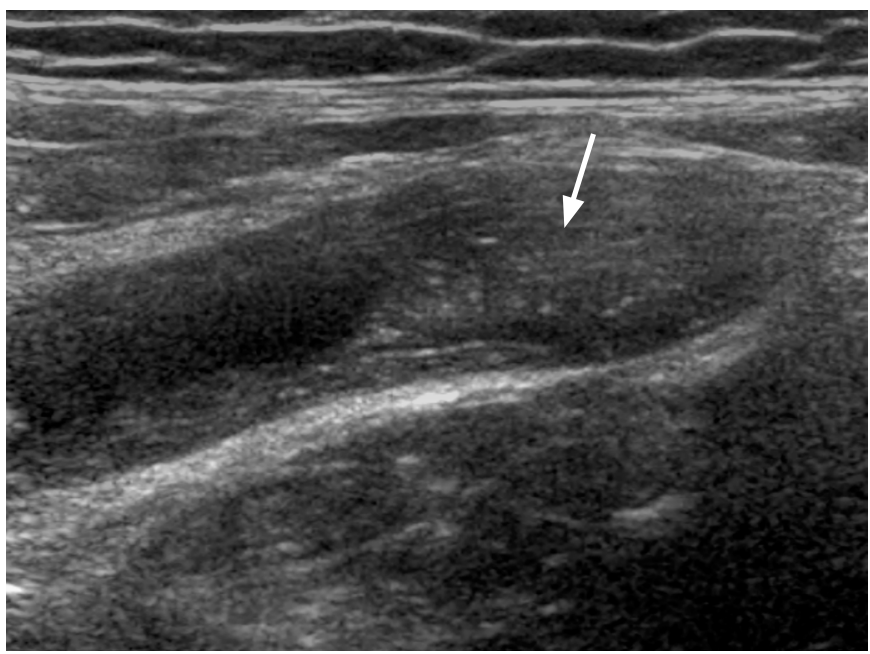

A

Fig. 15. Gangrenous appendicitis.

A, B. A grayscale image (A) and color Doppler image (B) show low echogenicity of the submucosal layer and lack of vascular flow of the appendiceal wall. Note the appendicoliths (arrows). 
positive results. Therefore, careful evaluation of the right lower quadrant is important to identify the primary cause of secondary inflammatory changes in the appendix.

\section{Mesenteric Lymphadenitis}

Mesenteric lymphadenitis is a benign, self-limiting disease. It arises from a primary inflammatory process or secondary inflammatory changes due to abdominal disease. Mesenteric lymphadenitis is clinical disease that is diagnosed after excluding other causes of abdominal pain. Since mesenteric LN enlargement is the only apparent finding, US is important for excluding other possible causes of abdominal pain.

Various normal ranges of $L N$ size have been reported, usually falling within 4-20 $\mathrm{mm}$ in the short axis. LNs $>5 \mathrm{~mm}$ in the short axis are common in normal, healthy children [31]. Enlarged

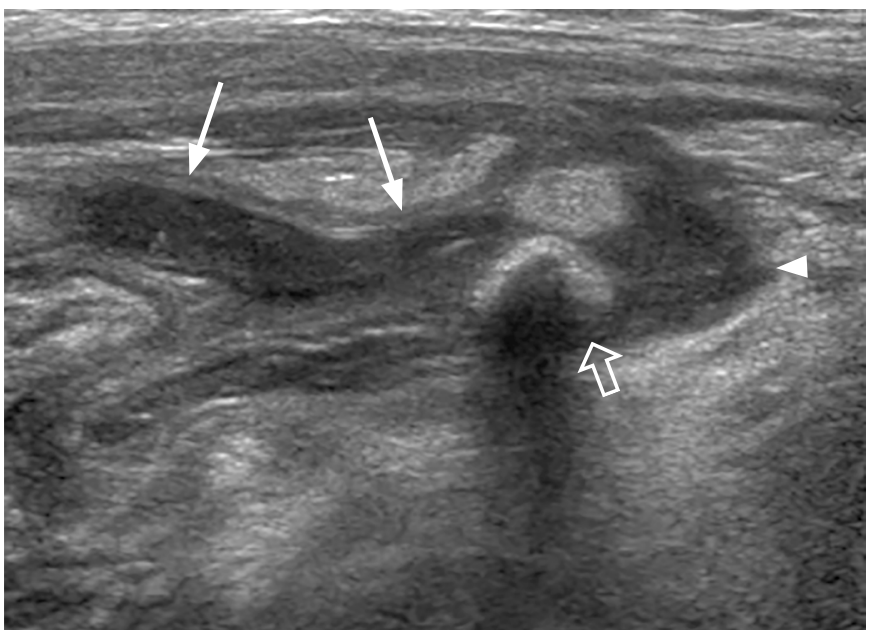

A

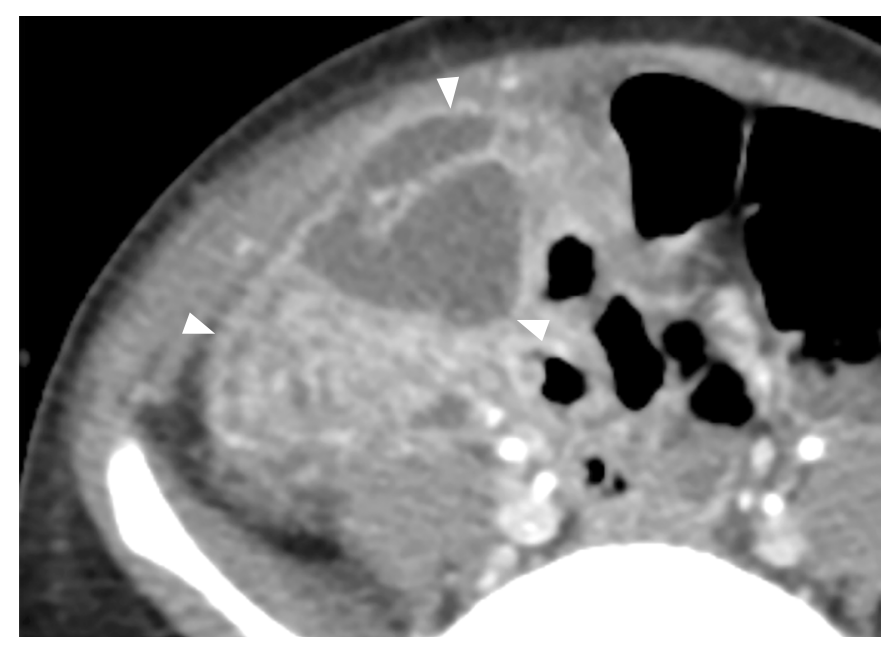

mesenteric LNs are frequently seen in pediatric patients, however, particularly those age $<10$ years. Three or more $L N s>5 \mathrm{~mm}$ in the short axis can be considered abnormal [32], although another study suggested that a cluster of three or more $L N s \geq 10 \mathrm{~mm}$ in the short axis should be diagnosed as mesenteric lymphadenopathy in the setting of a normal appendix [31].

Enlarged mesenteric LNs are often oval, with or without increased echogenicity of the perinodal fat tissue. A preserved fatty hilum serves as an echogenic area at the center of the LN. On color Doppler scans, central vascular pedicles are seen with or without increased vascularity (Fig. 17). It is important that radiologists evaluate whether inflammation is present in the appendix and GI tract. Malignant LNs should be suspected when they have a rounded shape rather than being oval, there is loss of the fatty hilum, and/or the LN has an eccentrically thickening cortex.

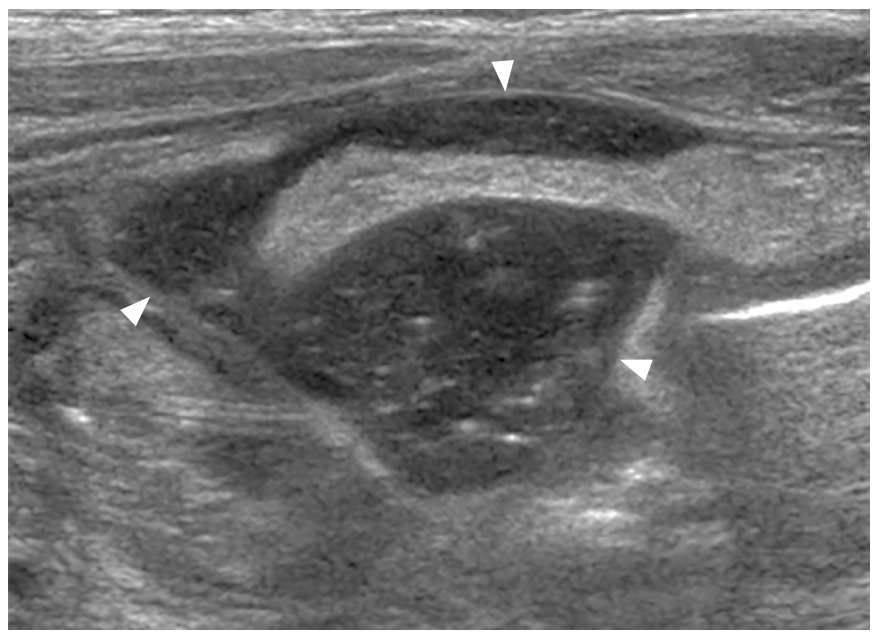

B

Fig. 16. Perforated appendix in a 10-month-old patient who presented with a fever of unknown origin.

A, B. Grayscale images show an appendix (arrows) dilated with periappendiceal fluid collection (arrowheads) with a low-level echo. Note the appendicolith in the appendix (open arrow) and increased echogenicity of the periappendiceal fat. C. A computed tomography image shows inflammatory phlegmon and abscess formation (arrowheads) in the right lower quadrant of the abdomen. 


\section{Henoch-Schönlein Purpura}

HSP is systemic vasculitis that can involve the GI tract. As a common cause of abdominal pain in children, it manifests as abdominal pain and bowel wall thickening in $50 \%-60 \%$ of patients [33]. It frequently involves the duodenum and small bowel, although it can affect the entire GI tract, mimicking acute appendicitis. Abdominal pain can forewarn of skin manifestations. Therefore, if a patient has severe bowel wall thickening in the duodenum and proximal small bowel, HSP should be considered even though skin lesions have not yet appeared.

A common sonographic finding is circumferential bowel wall thickening involving the duodenum and proximal jejunum due to intramural hemorrhage. HSP, however, can involve any segment of the bowel (Fig. 18). Focal intramural hematoma can be seen as an echogenic lesion in the mucosa or submucosa of the bowel. Bowel wall thickening due to intramural hematoma may show mean a maximal thickness of $9 \mathrm{~mm}$ and multifocal skip involvement $[34,35]$. In addition, hyperemia of the bowel wall can be seen on a color Doppler study. Intramural hematoma can be a lead point of

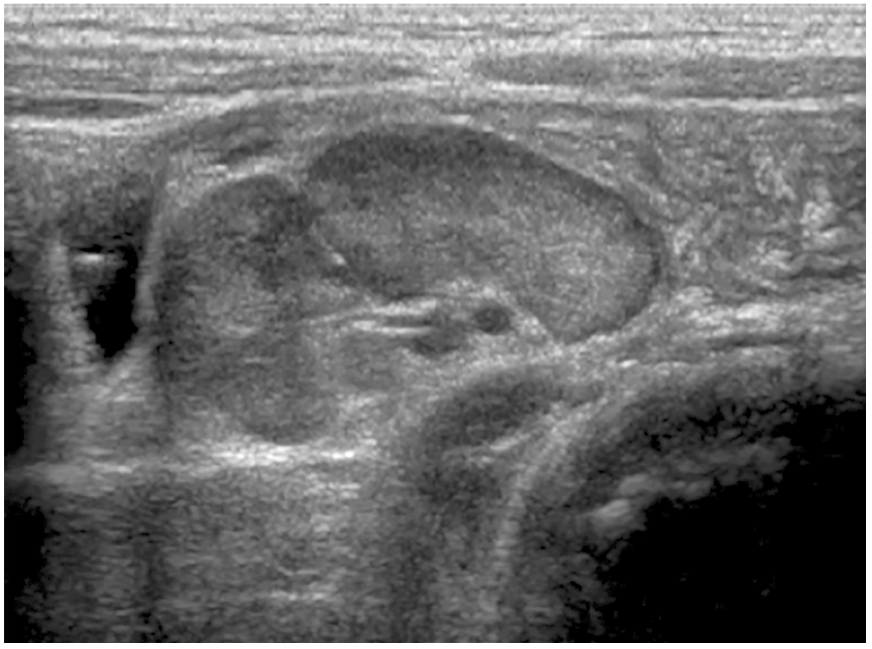

A

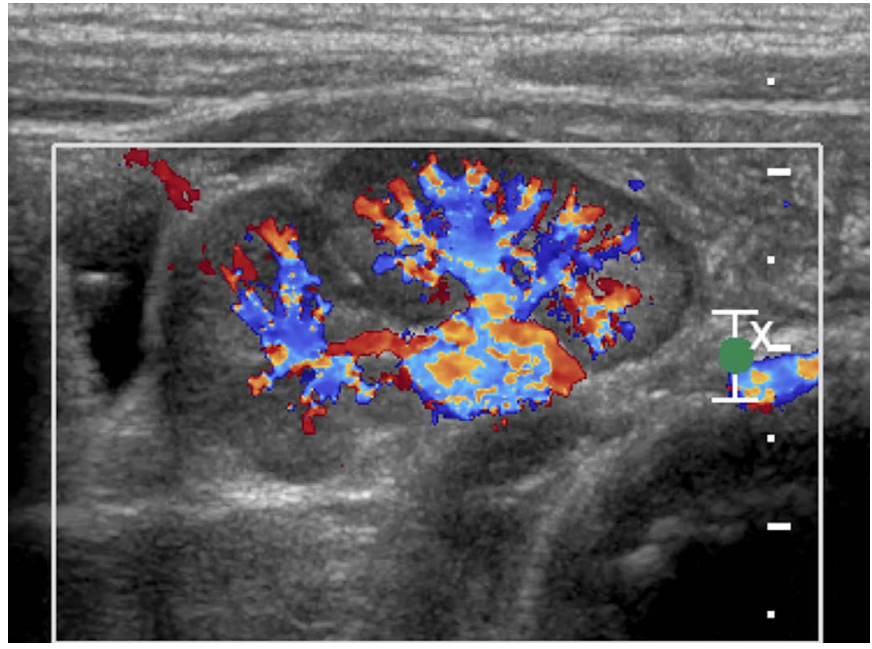

B

Fig. 17. Mesenteric lymphadenitis in a 7-year-old patient who presented with abdominal pain.

A, B. Grayscale (A) and color Doppler (B) images show an enlarged mesenteric lymph node with hyperemic changes. The lymph node is oval and contains preserved fatty hilum and a central vascular pedicle.

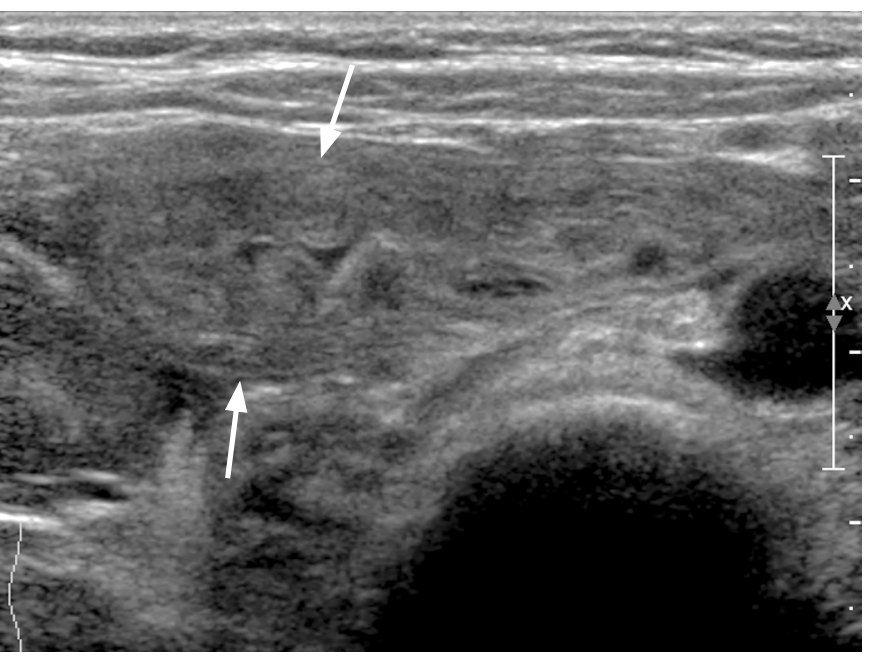

A

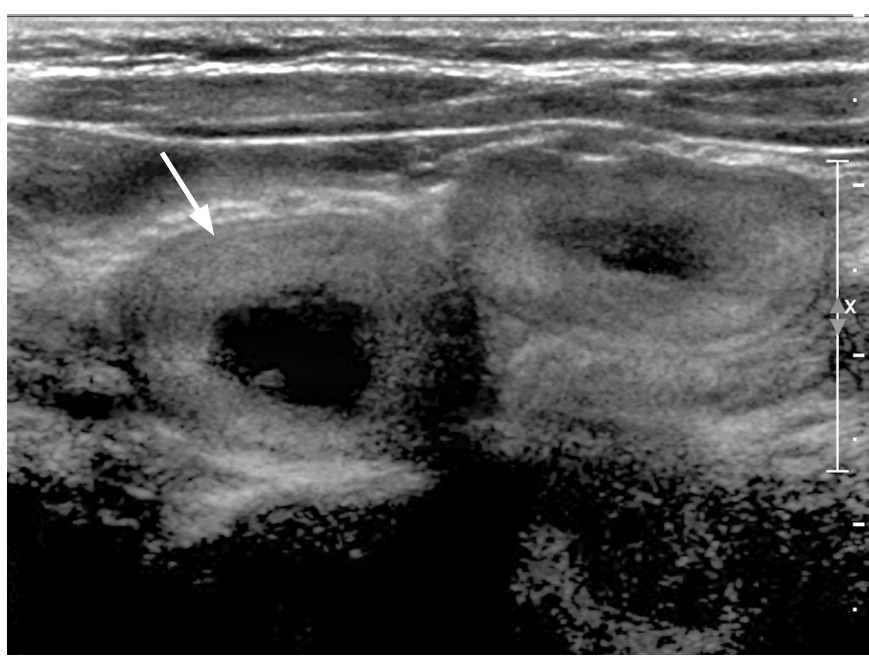

B

Fig. 18. Henoch-Schönlein purpura involving the gastrointestinal tract of a 6 -year-old patient.

$A, B$. Grayscale images of the duodenum (A) and jejunum (B) show concentric bowel wall thickening with slightly increased echogenicity of the bowel wall (arrows). 


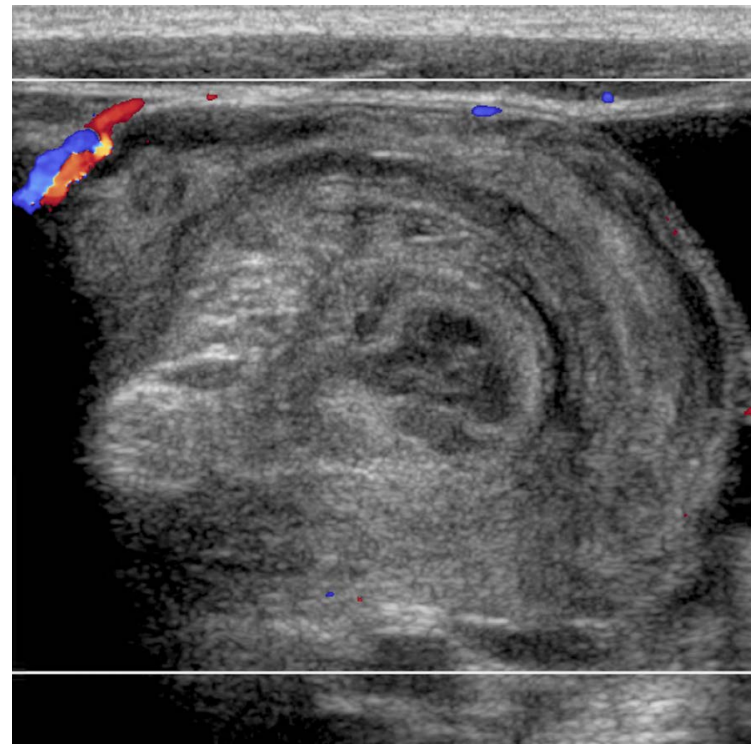

A

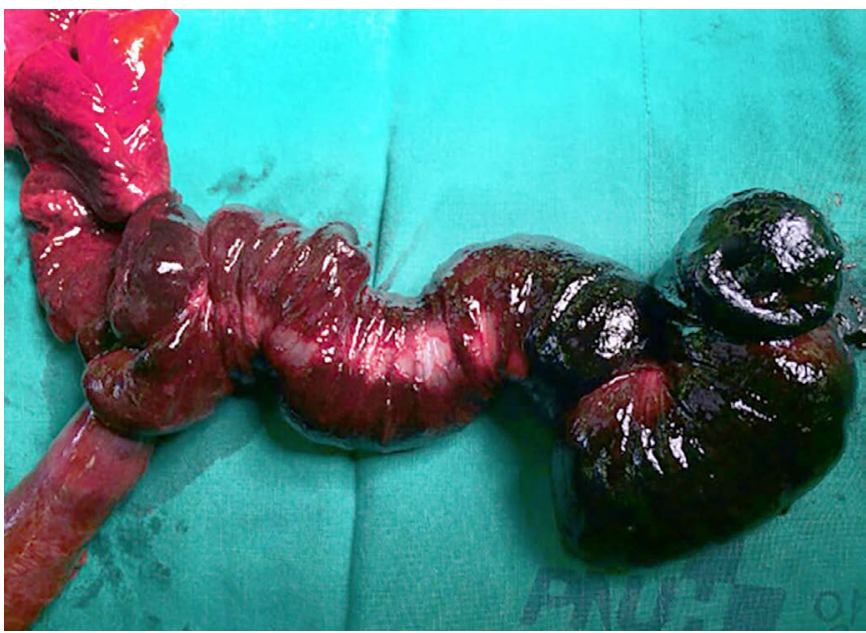

C

intussusception (Fig. 19).

\section{Omental Infarction}

Omental infarction is a rare disease in children, although $15 \%$ of all cases occur in pediatric patients [20]. This disease is now identified more frequently because of the increased prevalence of obesity and the increasing utilization of computed tomography (CT) and US. Omental infarction commonly presents with right-side abdominal pain that is associated with $\mathrm{Gl}$ symptoms such as anorexia, nausea, and vomiting. It thus mimics acute appendicitis.

The typical sonographic finding is an ovoid, echogenic mass located between the abdominal wall and the bowel, frequently in the right upper quadrant (Fig. 20). On a color Doppler study, it

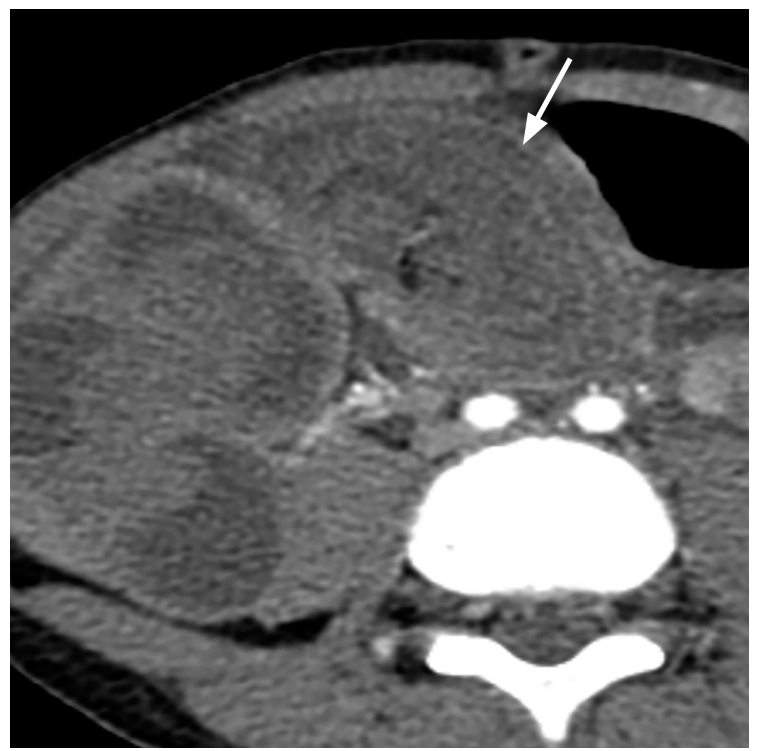

B

Fig. 19. Small bowel intussusception due to Henoch-Schönlein purpura in a 6-year-old patient who presented with abdominal pain.

A. A color Doppler image shows small bowel intussusception with lack of vascularity. B. A computed tomography image reveals small bowel intussusception (arrow) without normal bowel enhancement. C. A photograph of the surgical specimen shows long segmental small bowel intussusception with strangulation and severe bowel wall thickening.

may appear as peripheral hyperemic changes. Although US has good diagnostic accuracy for this diagnosis, the accuracy is variable because it is operator-dependent. US plays an important role in excluding appendicitis and other diseases of the GI tract. Early detection of omental infarction can prevent unnecessary surgical intervention or the need for CT scanning.

\section{Summary}

US is the modality of choice for the initial evaluation of acute abdominal pain in pediatric patients because of their small body habitus and the presence of less fat tissue in the abdominal wall and peritoneal cavity. Thus, they have an optimal sonic window, unlike adult patients. Proper selection of the transducers, optimal 


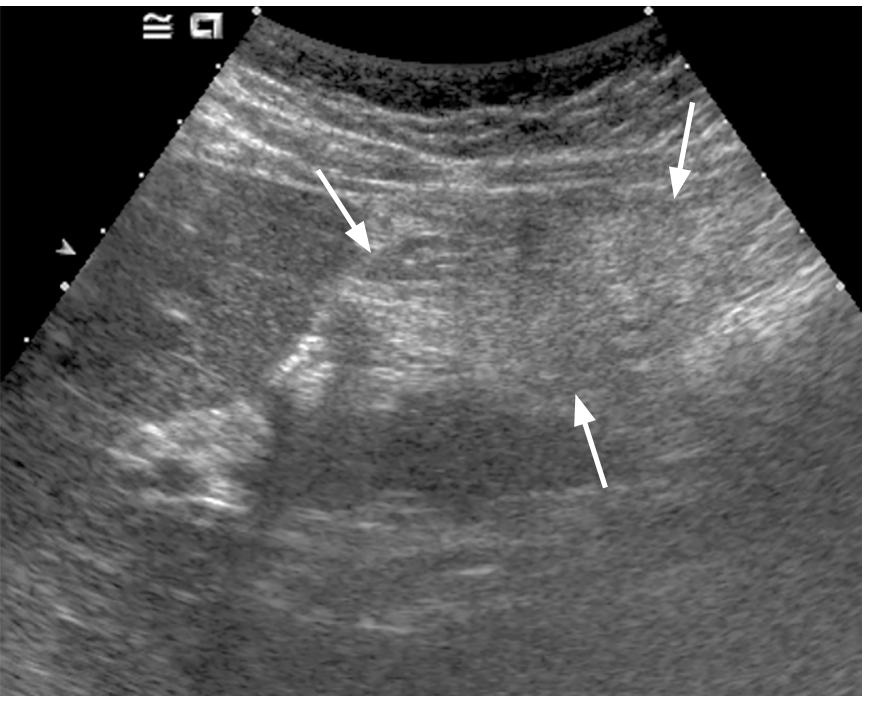

A

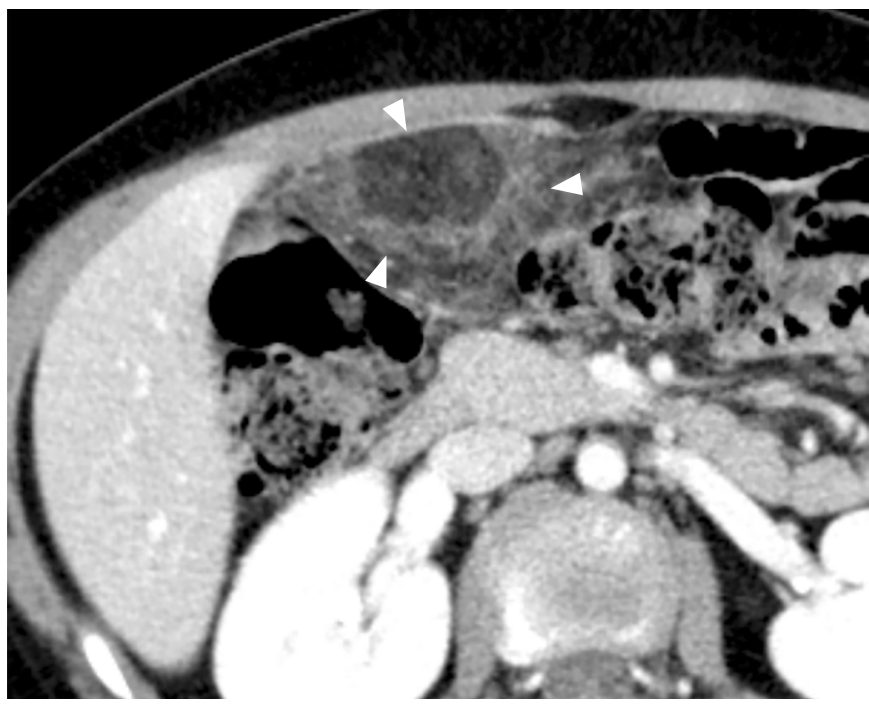

B

Fig. 20. Omental infarction in a 9-year-old patient who presented with acute abdominal pain.

A. A sonogram shows an area of heterogeneously increased echogenicity abutting the abdominal wall (arrows). B. A computed tomography image shows a focal area of fat stranded with a hyperattenuated peripheral halo (arrowheads).

positioning, and the use of graded compression techniques improve the visualization of bowel diseases. US can diagnose several diseases that cause abdominal pain and can differentiate among various medical and surgical problems in pediatric patients. Careful evaluation of bowel wall thickening combined with ancillary findings such as fluid collection, increased echogenicity of mesenteric fat tissue, enlarged LNs, hyperemic bowel changes, and abnormal bowel peristalsis increase the diagnostic capability of US. Several disorders mimicking acute appendicitis (mesenteric lymphadenitis, HSP, and omental infarction) should be considered when performing US in pediatric patients with right-side abdominal pain and a normal appendix.

ORCID: Jae-Yeon Hwang: http://orcid.org/0000-0003-2777-3444

\section{Conflict of Interest}

No potential conflict of interest relevant to this article was reported.

\section{Supplementary Material}

Video clip 1. A movie clip shows graded compression technique of the abdomen (https://doi.org/10.14366/usg.16052.v001).

Video clip 2. A movie clip shows graded compression technique of the upper abdomen (https://doi.org/10.14366/usg.16052.v002).

Video clip 3. Movie clip shows typical course of the sigmoid colon (https://doi.org/10.14366/usg.16052.v003).
Video clip 4. A movie clip shows normal retroperitoneal course of the duodenal third portion (https://doi.org/10.14366/usg. 16052. v004).

Video clip 5. A movie clip shows "whirlpool" sign in a patient with midgut volvulus (https://doi.org/10.14366/usg.16052.v005).

Video clip 6. A movie clip shows abnormal location of the superior mesenteric artery and vein due to off-center scanning (https://doi. org/10.14366/usg.16052.v006).

Video clip 7. A movie clip shows normal couterclockwise rotation of the superior mesenteric vein (https://doi.org/10.14366/usg. 16052. v007).

Video clip 8. A movie clip shows normal position and appearance of pylorus (https://doi.org/10.14366/usg.16052.v008).

Video clip 9. A movie clip shows passage of fluid through the pylorus in a normal patient (https://doi.org/10.14366/usg. 16052. v009).

Video clip 10. A movie clip shows normal location of the ileocecal valve, terminal ileum, and appendix (https://doi.org/10.14366/ usg. 16052.v010).

Video clip 11. A movie clip shows the normal apperance and course 
of pelvic brim type appendix (https://doi.org/10.14366/usg.16052. v011).

Video clip 12. A movie clip shows posterior compression technique (https://doi.org/10.14366/usg.16052.v012).

Video clip 13. A movie clip shows acute calculous appendicitis (https://doi.org/10.14366/usg.16052.v013).

Video clip 14. A movie clip shows acute appendicitis limited to the tip of the appendix (https://doi.org/10.14366/usg.16052.v014).

\section{References}

1. Lee JH, Jeong YK, Park KB, Park JK, Jeong AK, Hwang JC. Operatordependent techniques for graded compression sonography to detect the appendix and diagnose acute appendicitis. AJR Am J Roentgenol 2005;184:91-97.

2. Shirah BH, Shirah HA, Alhaidari WA, Elraghi MA, Chughtai MA. The role of preoperative graded compression ultrasound in detecting acute appendicitis and influencing the negative appendectomy rate. Abdom Radiol (NY) 2017;42:109-114.

3. Thomson M, Rao P, Berger L, Rawat D. Graded compression and power Doppler ultrasonography versus endoscopy to assess paediatric Crohn disease activity pre- and posttreatment. J Pediatr Gastroenterol Nutr 2012;54:404-408.

4. Fleischer AC, Muhletaler CA, James AE Jr. Sonographic assessment of the bowel wall. AJR Am J Roentgenol 1981;136:887-891.

5. Haber HP, Stern M. Intestinal ultrasonography in children and young adults: bowel wall thickness is age dependent. J Ultrasound Med 2000;19:315-321.

6. Siegel MJ. Pediatric sonography. 4th ed. Philadelphia, PA: Lippincott Williams \& Wilkins, 2011.

7. Schmidt T, Hohl C, Haage $P$, Honnef $D$, Mahnken AH, Krombach $G$, et al. Phase-inversion tissue harmonic imaging compared to fundamental B-mode ultrasound in the evaluation of the pathology of large and small bowel. Eur Radiol 2005;15:2021-2030.

8. Menten R, Reding R, Godding V, Dumitriu D, Clapuyt P. Sonographic assessment of the retroperitoneal position of the third portion of the duodenum: an indicator of normal intestinal rotation. Pediatr Radiol 2012;42:941-945.

9. Loyer E, Eggli KD. Sonographic evaluation of superior mesenteric vascular relationship in malrotation. Pediatr Radiol 1989;19:173175.

10. Karmazyn B. Duodenum between the aorta and the SMA does not exclude malrotation. Pediatr Radiol 2013;43:121-122.

11. Hernanz-Schulman M. Infantile hypertrophic pyloric stenosis. Radiology 2003;227:319-331.
12. Niedzielski J, Kobielski A, Sokal J, Krakos M. Accuracy of sonographic criteria in the decision for surgical treatment in infantile hypertrophic pyloric stenosis. Arch Med Sci 2011;7:508511.

13. Sivitz $A B$, Tejani $C$, Cohen $S G$. Evaluation of hypertrophic pyloric stenosis by pediatric emergency physician sonography. Acad Emerg Med 2013;20:646-651.

14. Stunden RJ, LeQuesne GW, Little KE. The improved ultrasound diagnosis of hypertrophic pyloric stenosis. Pediatr Radiol 1986;16:200-205.

15. Hernanz-Schulman M. Pyloric stenosis: role of imaging. Pediatr Radiol 2009;39 Suppl 2:S134-S139.

16. O'Keeffe FN, Stansberry SD, Swischuk LE, Hayden CK Jr. Antropyloric muscle thickness at US in infants: what is normal? Radiology 1991;178:827-830.

17. Hernanz-Schulman M, Sells LL, Ambrosino MM, Heller RM, Stein SM, Neblett WW 3rd. Hypertrophic pyloric stenosis in the infant without a palpable olive: accuracy of sonographic diagnosis. Radiology 1994;193:771-776.

18. Mandeville K, Chien M, Willyerd FA, Mandell G, Hostetler MA, Bulloch B. Intussusception: clinical presentations and imaging characteristics. Pediatr Emerg Care 2012;28:842-844.

19. Coley BD. Caffey's pediatric diagnostic imaging. 12th ed. Philadelphia, PA: Elsevier/Saunders, 2013.

20. Munden MM, Hill JG. Ultrasound of the acute abdomen in children. Ultrasound Clin 2010;5:113-135.

21. Navarro O, Dugougeat F, Kornecki A, Shuckett B, Alton DJ, Daneman A. The impact of imaging in the management of intussusception owing to pathologic lead points in children: a review of 43 cases. Pediatr Radiol 2000:30:594-603.

22. Mateen MA, Saleem S, Rao PC, Gangadhar V, Reddy DN. Transient small bowel intussusceptions: ultrasound findings and clinical significance. Abdom Imaging 2006;31:410-416.

23. Nance ML, Adamson WT, Hedrick HL. Appendicitis in the young child: a continuing diagnostic challenge. Pediatr Emerg Care 2000;16:160-162.

24. Lee SL, Stark R, Yaghoubian A, Shekherdimian S, Kaji A. Does age affect the outcomes and management of pediatric appendicitis? J Pediatr Surg 2011;46:2342-2345.

25. Schwartz KL, Gilad E, Sigalet D, Yu W, Wong AL. Neonatal acute appendicitis: a proposed algorithm for timely diagnosis. J Pediatr Surg 2011;46:2060-2064.

26. Colvin JM, Bachur R, Kharbanda A. The presentation of appendicitis in preadolescent children. Pediatr Emerg Care 2007;23:849-855.

27. Lee JH, Jeong YK, Hwang JC, Ham SY, Yang SO. Graded compression sonography with adjuvant use of a posterior manual compression technique in the sonographic diagnosis of acute appendicitis. AJR Am J Roentgenol 2002;178:863-868.

28. Wiersma F, Sramek A, Holscher HC. US features of the normal 
appendix and surrounding area in children. Radiology 2005;235: 1018-1022.

29. Patriquin HB, Garcier JM, Lafortune $M$, Yazbeck $S$, Russo P, Jequier $S$, et al. Appendicitis in children and young adults: Doppler sonographic-pathologic correlation. AJR Am J Roentgenol 1996;166:629-633.

30. Goldin AB, Khanna P, Thapa M, McBroom JA, Garrison MM, Parisi MT. Revised ultrasound criteria for appendicitis in children improve diagnostic accuracy. Pediatr Radiol 2011;41:993-999.

31. Simanovsky N, Hiller N. Importance of sonographic detection of enlarged abdominal lymph nodes in children. J Ultrasound Med 2007;26:581-584.

32. Swischuk LE, John SD. Mesenteric adenitis-acute ileitis: a constellation of findings definable with ultrasound. Emerg Radiol 1998:5:210-218.

33. Trapani S, Micheli A, Grisolia F, Resti M, Chiappini E, Falcini F, et al. Henoch Schonlein purpura in childhood: epidemiological and clinical analysis of 150 cases over a 5-year period and review of literature. Semin Arthritis Rheum 2005;35:143-153.

34. Siskind BN, Burrell MI, Pun H, Russo R Jr, Levin W. CT demonstration of gastrointestinal involvement in Henoch-Schonlein syndrome. Gastrointest Radiol 1985;10:352-354.

35. Jeong $Y K$, Ha HK, Yoon $C H$, Gong G, Kim PN, Lee MG, et al. Gastrointestinal involvement in Henoch-Schonlein syndrome: CT findings. AJR Am J Roentgenol 1997;168:965-968. 